\title{
Effect of atmospheric circulation on surface air temperature trends in years 1979-2018
}

\author{
Jouni Räisänen ${ }^{1}$ (D)
}

Received: 28 February 2020 / Accepted: 15 December 2020 / Published online: 4 January 2021

(C) The Author(s) 2021

\begin{abstract}
The effect of atmospheric circulation on monthly, seasonal and annual mean surface air temperature trends in the years 1979-2018 is studied by applying a trajectory-based method on the European Centre for Medium-Range Weather Forecasts ERA5 reanalysis data. To the extent that the method captures the effects of atmospheric circulation, the results suggest that circulation trends only had a minor impact on observed annual mean temperature trends in most areas. Exceptions include, for example, a decrease in annual mean warming by about $1{ }^{\circ} \mathrm{C}$ in western Siberia, and increased warming in central Europe and the Arctic Ocean. However, the effect of circulation trends on seasonal and particularly monthly temperature trends is more substantial. Subtracting the effect of circulation changes from the ERA5 temperature trends leaves residual trends with a smoother annual cycle than the original trends. The residual monthly mean temperature trends also tend to agree better with the multi-model mean temperature trends from models in the 5th Coupled Model Intercomparison Project (CMIP5) than the original ERA5 trends do, with a $42 \%$ decrease in the mean square difference over the global land area. However, the corresponding decrease in the mean square difference of the annual mean temperature trends is only $6 \%$.
\end{abstract}

Keywords Atmospheric circulation · Trajectory $\cdot$ Surface air temperature $\cdot$ Climate change $\cdot$ ERA5 $\cdot$ CMIP5

\section{Introduction}

The evolution of climate reflects a superposition of externally forced changes with internally generated natural variability. Although such internal variability is largely smoothed out in averages over several tens of model simulations, it both complicates the interpretation of observed climate changes and is an important uncertainty in projections of regional climate change in the next several decades (Deser et al. 2012, 2014, 2016; Hawkins and Sutton 2009, 2010). A major fraction of internal variability of surface climate results from variations in atmospheric circulation (Parker 2009; Deser et al. 2012, 2014; Saffioti et al. 2016, 2017). Specifically, surface air temperature is affected by

Supplementary Information The online version contains supplementary material available at https://doi.org/10.1007/s0038 2-020-05590-y.

Jouni Räisänen

jouni.raisanen@helsinki.fi

1 Institute for Atmospheric and Earth System Research/ Physics, Faculty of Science, FI-00014 University of Helsinki, P.O. Box 64, Helsinki, Finland atmospheric circulation both via advection and because circulation modulates diabatic heating, for example by regulating cloudiness (Holmes et al. 2016; Räisänen 2019a).

Several studies have attempted to estimate the effect of atmospheric circulation changes on recently observed temperature changes in various parts of the world. Many of them have related the variations of temperature to the distribution of monthly mean sea level pressure (SLP), using a variety of statistical techniques. For example, Wallace et al. (2012) and Smoliak et al. (2015) applied partial linear regression, Deser et al. (2016) constructed analogues, and Saffioti et al. (2016) linear regression using the principal components of SLP as the predictors. In an alternative, more data intensive approach, Parker (2009) used two-dimensional and Räisänen (2019b, hereafter R19) three-dimensional trajectories of air calculated from 6-hourly pressure or wind data.

A wide range of circulation-related temperature trends have been reported in these studies. Both Wallace et al. (2012) and Smoliak et al. (2015) found a pronounced circulation-induced cold season (November to April, NDJFMA) warming over the Northern Hemisphere continents. As averaged over land north of $40^{\circ} \mathrm{N}$, circulation changes were found to explain about $0.7^{\circ} \mathrm{C}$ of the observed $1.7^{\circ} \mathrm{C}$ 
NDJFMA warming in 1965-2000. Smoliak et al. (2015) also repeated this analysis for the longer period 1920-2011 with quite similar results. Similarly, Deser et al. (2016) found atmospheric circulation to have caused, on the average, a third of the observed winter (December-January-February, DJF) warming in North America in the years 1963-2012. Parker (2009) also found a positive albeit small $\left(0.09{ }^{\circ} \mathrm{C}\right)$ circulation-induced anomaly in the annual mean of the Central England Temperature in the last decade of his study (1996-2005). Conversely, Saffioti et al. (2016) reported a circulation-related winter cooling of nearly $0.8^{\circ} \mathrm{C}$ per decade in Europe in the years 1989-2012. Some of these differences may be method-related, but as argued later in Sect. 7, differences in the periods for which the trends have been calculated are probably more important.

Nevertheless, the findings from the cited studies also share an important similarity: circulation adjustment (i.e. subtraction of the circulation effect from the observed temperatures) tends to leave residual time series and trends that behave in a more intuitive way than the observed temperatures. Smoliak et al. (2015) found circulation changes to reconcile much of the spatial variability in the observed cold season warming, and subtraction of the circulation effect made the time evolution of the cold season temperatures more consistent with the warm season temperatures. Similarly, the circulation adjustment in R19 greatly smoothed the seasonal cycle of monthly mean temperature trends in Finland in the years 1979-2018. Furthermore, Wallace et al. (2012), Deser et al. (2016), Saffioti et al. (2016) and R19 all found the circulation-adjusted temperature trends to agree better with multi or single model ensemble mean temperature trends in climate models than the original observed trends did.

Most of this earlier research has focused on the Northern Hemisphere continents during the winter half-year, probably due to at least two reasons. First, the large climatological temperature gradients in the wintertime Northern Hemisphere, both in the north-south direction and between land and sea, increase the sensitivity of temperature to the prevailing wind direction. Second, the atmospheric circulation during the Northern Hemisphere winter exhibits large interannual and interdecadal variability. In particular, a pronounced shift towards the positive phase of the North Atlantic Oscillation and the Northern Annular Mode was observed between the 1960s and the early 1990s (Hurrell and van Loon 1997; Thomson and Wallace 1998), although this shift has been at least partly reversed in the past two decades (Iles and Hegerl 2017). Regardless, variations in atmospheric circulation are also expected to affect temperature trends in other seasons and areas, for which less research has been available this far.

This paper aims to quantify circulation-related trends in annual, seasonal and monthly mean temperatures during the last four decades (1979-2018), using the trajectory based approach of R19. In contrast to the earlier research, the analysis is worldwide, although the main focus is on extratropical continents where atmospheric circulation (as described by the R19 approach) explains the largest fraction of interannual temperature variability.

A key motivation for quantifying the circulation effect is to find out how temperature would have changed without circulation changes. We would generally expect these residual trends to approximate the underlying forced climate change better than the observed trends do, although with two obvious caveats. First, a fraction of unforced temperature variability is caused by variations in sea surface temperature (SST) and ice cover, and the effects of this variability are only captured in our analysis to the extent that the sea surface conditions affect the atmospheric circulation. Second, some of the observed circulation changes may have been externally forced, the most prominent example being the effect of ozone depletion on the Southern Hemisphere circulation (Polvani 2011). Nonetheless, forced circulation changes in climate model simulations tend to be relatively small (Selten et al. 2004; Wallace et al. 2012; Deser et al. 2016; Saffioti et al. 2017). If this also holds for the real world, most of the atmospheric circulation changes observed during the past few decades have likely resulted from internal variability and not from external forcing.

The outline of the paper is as follows. Section 2 describes the data sets used and gives a summary of the trajectorybased regression approach. Section 3 documents the performance of the trajectory method in explaining interannual temperature variability. The circulation-related annual and seasonal mean temperature trends are described in Sect. 4, and some areas are selected for closer case studies of monthly temperature trends in Sect. 5. A key result is that the importance of atmospheric circulation increases when proceeding from annual to seasonal and monthly trends, and this aspect is further quantified in Sect. 6 using Fourier analysis. A brief comparison of the circulation-related temperature trends with two earlier studies is provided in Sect. 7. Finally, the main conclusions are given in Sect. 8 . The details of the regression approach are discussed in the electronic Supplementary material, which also includes several additional figures. Furthermore, selected GrADS scripts and data are available on-line to allow a more detailed exploration of the effect of circulation changes on regional scales (see Data and Code availability).

\section{Data and methods}

For the trajectory-based analysis, data from the European Centre for Medium-Range Weather Forecasts ERA5 reanalysis (Hersbach et al. 2020) are used. The study covers the 
years 1979-2018, as dictated by the availability of ERA5 when this research was started. The beginning of this period also coincides with the beginning of the meteorological satellite era, during which reanalysis data are expected to be more reliable than before. ERA5 horizontal winds and vertical motion $(\omega)$ at 6-hourly time resolution and coarsegrained to a $50 \mathrm{hPa}$ vertical and $2.5^{\circ} \times 2.5^{\circ}$ horizontal grid are used to calculate back trajectories of air up to $168 \mathrm{~h}$ before its arrival to each target grid point at 7 different pressure levels from 550 to $1000 \mathrm{hPa}$. Six-hourly ERA5 data are also used to compute daily and monthly mean values of surface air ( $2 \mathrm{~m})$ temperature.

For comparison, temperature trends were also calculated for the same 42 Coupled Model Intercomparison Project 5 (CMIP5; Taylor et al. 2012) climate models as used in the Intergovernmental Panel on Climate Change 5th assessment report (Collins et al. 2013). These trends are based on a concatenation of the historical (1979-2005) and RCP4.5 simulations (2006-2018). Since the four RCP scenarios are still close to each other in the early twenty-first century, the choice between them is largely arbitrary (van Vuuren et al. 2011). The main focus is on the CMIP5 multi-model mean trends, which (unlike the trends in the individual model runs) are expected to be only modestly affected by circulation changes. Ideally, the circulation effect should also be eliminated from the CMIP5 simulations to allow a clean comparison with the ERA5 residual trends, but the data available for CMIP5 are insufficient for the trajectory calculation.

The trajectory-based regression method used to quantify the effect of atmospheric circulation on surface air temperature anomalies is largely unchanged from R19. The method is based on the expectation that air masses of different origins cause different characteristic temperature anomalies at a given location. For example, over the European sector of the Arctic Ocean air masses originating from the eastern Arctic Ocean and from northern Siberia tend to lead to anomalously cold conditions during winter, whereas air masses from the relatively mild North Atlantic and European sector lead to anomalously warm conditions during the same season. We also expect vertical motion along the trajectories to play a role, due to both the associated adiabatic cooling or heating of air parcels and the effects of vertical motion on latent heat release and cloudiness.

As briefly described below, the method has four main steps. Further technical details and justification for the adopted choices are provided in the Supplementary material and in R19.

1. Estimation of daily temperature anomalies from trajectory origin. Least-squares multiple linear regression in three-dimensional space was used to relate the daily temperature anomalies (relative to the mean for the same day in years 1979-2018, without smoothing the seasonal cycle) to the start coordinates of the trajectories ending at the target grid point. The regression coefficients were calculated separately for each calendar month. See Section S1.1 in the Supplementary material for details.

2. Averaging and rescaling of daily temperature anomalies to monthly mean temperature anomalies. The resulting circulation-related daily mean temperature anomalies were averaged over each month and these monthly averages were then rescaled using linear regression against the ERA5 monthly mean temperature anomalies (Section S1.2 in the Supplementary material).

3. Combination of monthly temperature anomaly estimates based on trajectories with different duration and end level. Steps 1-2 were repeated for 7 durations $(24,48, \ldots$ $168 \mathrm{~h})$ and 7 end levels $(550,625, \ldots 1000 \mathrm{hPa})$ of trajectories. After this, R19 simply averaged the resulting 49 circulation-related temperature anomalies, which was found to work well for Finland. Here, two modifications were made to improve the performance of the method in a global domain. First, trajectory end levels that exceed the climatological monthly mean surface pressure in the target point by $75 \mathrm{hPa}$ or more were excluded. Thus, at most one level below the actual surface was used. Second, a weighting was applied to give more weight to those duration-end level combinations for which the mean square error of the regression-based temperature anomalies relative to the actual ERA5 temperature anomalies was smaller. See Section S1.4 in the Supplementary material for the details of the weighting, and Section S1.3 for a discussion of why different end levels and trajectory durations were used in the first place.

4. Final rescaling. Last, a new linear rescaling was made by regressing the temperature anomaly estimate from step $3\left(\left\langle\Delta T_{2}\right\rangle\right.$ in Eq. (S6)) against the ERA5 monthly mean temperature anomalies (Eq. (S7)). This rescaling, which generally increases the magnitude of the circulation-related anomalies, is justified by the smaller random errors in $\left\langle\Delta T_{2}\right\rangle$ compared with the estimates based on individual trajectory end level-duration combinations (Supplementary material, Section S1.4).

All the regression coefficients as well as the weights used in step 3 were calculated separately for each year, using only the data for the other 39 years. This eliminates artificial skill by making the predicted temperature anomalies independent from the ERA5 temperature anomaly. In addition, the predictor and predictand time series were linearly detrended when deriving the regression coefficients, to avoid aliasing between circulation-related variability and non-circulationrelated climate change.

To indicate which of the circulation-related temperature trends deserve the most attention, their significance 
is evaluated following R19. The question addressed is not whether the circulation trends that were realized between 1979 and 2018 are significant relative to interannual variability, but whether their effect on the simultaneous temperature trends can be determined reliably. The underlying assumption is that, without circulation variability, only forced climate change would have been present, and temperature would thus have changed approximately linearly with time from 1979 to 2018. In this case, all the detrended interannual variability in the residual (ERA5-predicted circulation effect) temperatures would result from the inability of the trajectory method to fully represent the effects of atmospheric circulation. Circulation-related temperature trends are considered significant ( $10 \%$ level, two-sided test) when exceeding $\pm 1.686 \sigma_{\text {trend }}$, where $\sigma_{\text {trend }}$ is calculated from the interannual variance of the detrended residuals (Eq. (6) in R19). This test is conservative particularly over the oceans, where the regression residuals are amplified by lower-frequency SST and sea ice variability unrelated to the concurrent atmospheric circulation.

\section{Performance of the regression model}

Figure 1 quantifies the performance of the trajectory-based regression by the explained variance

$E=1-\frac{{\overline{\Delta T_{r e s}^{2}}}^{1979-2018}}{\Delta T_{E R A 5}^{2}}{ }^{1979-2018}$

where $\Delta T_{\text {res }}$ is the difference between the analyzed $\left(\Delta T_{E R A 5}\right)$ and predicted temperature anomalies, and both of these have been linearly detrended over 1979-2018 to exclude longterm climate change. The method generally works better over land than ocean. This is as expected, because the inbuilt assumption that daily and monthly temperature anomalies share similar dynamics is less likely to hold over the oceans, where the surface heat capacity is large. Furthermore, temperature variability over the oceans is directly affected by the heat transported by ocean currents as well as the atmospheric circulation. In addition, the explained variance is typically larger in extratropical than tropical latitudes. This is consistent with the larger temperature gradients and more variable atmospheric circulation in the extratropics. Note, though, that the method also includes information on vertical

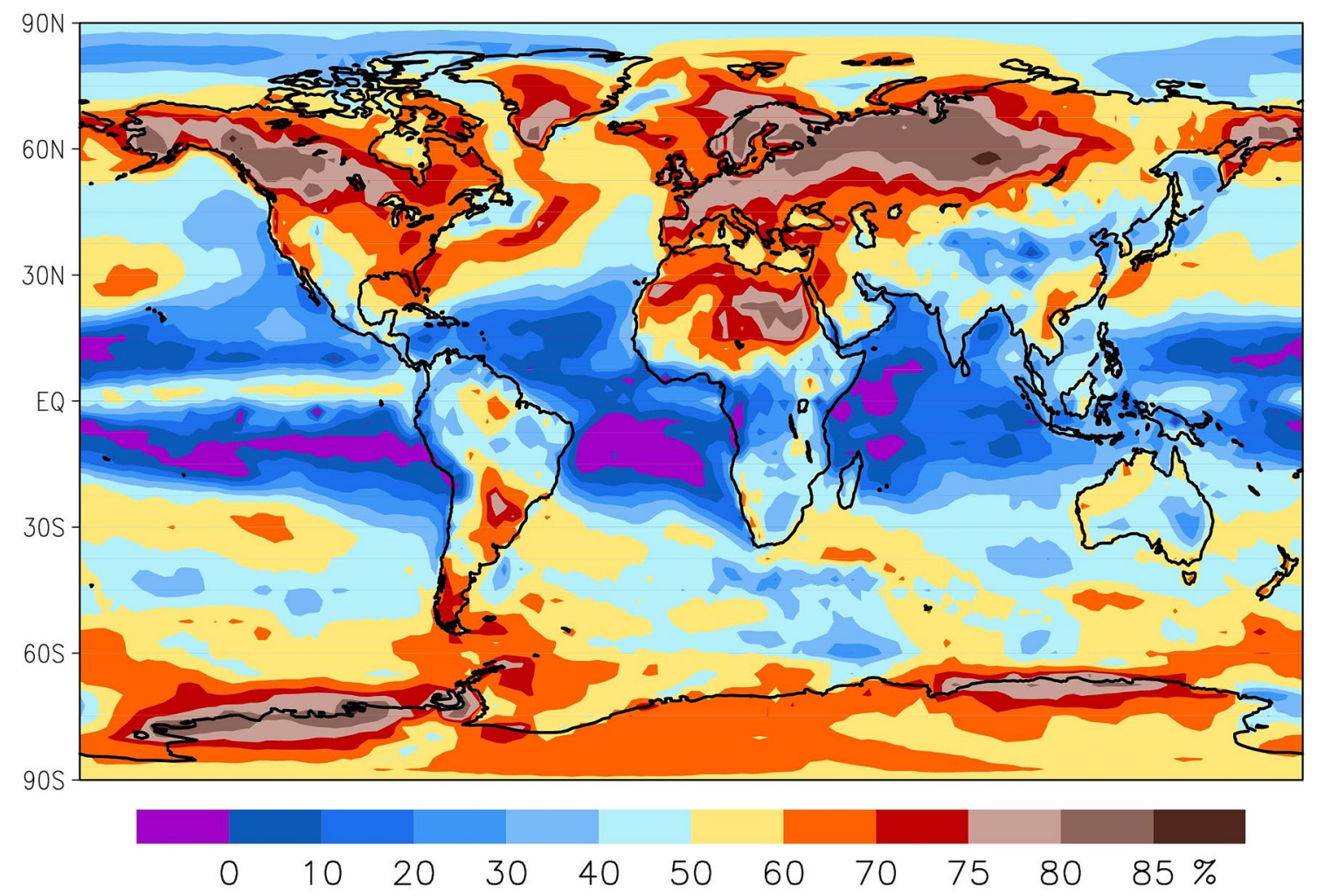

Fig. 1 Explained variance of detrended monthly mean temperature anomalies (circulation-based prediction vs. ERA5). Note that the simple latitude-longitude projection used in global maps in this paper over-emphasizes high-latitude areas relative to lower latitudes 
motion and thus its impact on cloudiness and the surface radiation balance (cf. Sect. 5.6 below).

In some tropical areas, where the dependence of temperature on the origin of the trajectories is weak, $E<0$. This results from the out-of-sample procedure used, in which the data for the predicted year is excluded when deriving the regression coefficients and weights discussed in Sect. 2 and the Supplementary material.

As a global 12 -month mean value, $E=61 \%$ as a varianceweighted average that gives more weight to areas and months with larger temperature variability. The corresponding mean values for land and sea are $67 \%$ and $51 \%$ (Table S1). Locally, over $80 \%$ of the detrended monthly mean temperature variance is explained in parts of northwestern Eurasia, northwestern North America, along the Antarctic coastline and, perhaps more surprisingly, in northeastern Africa. In both hemispheres, the explained variance tends to be larger in winter than in summer (Fig. S8).
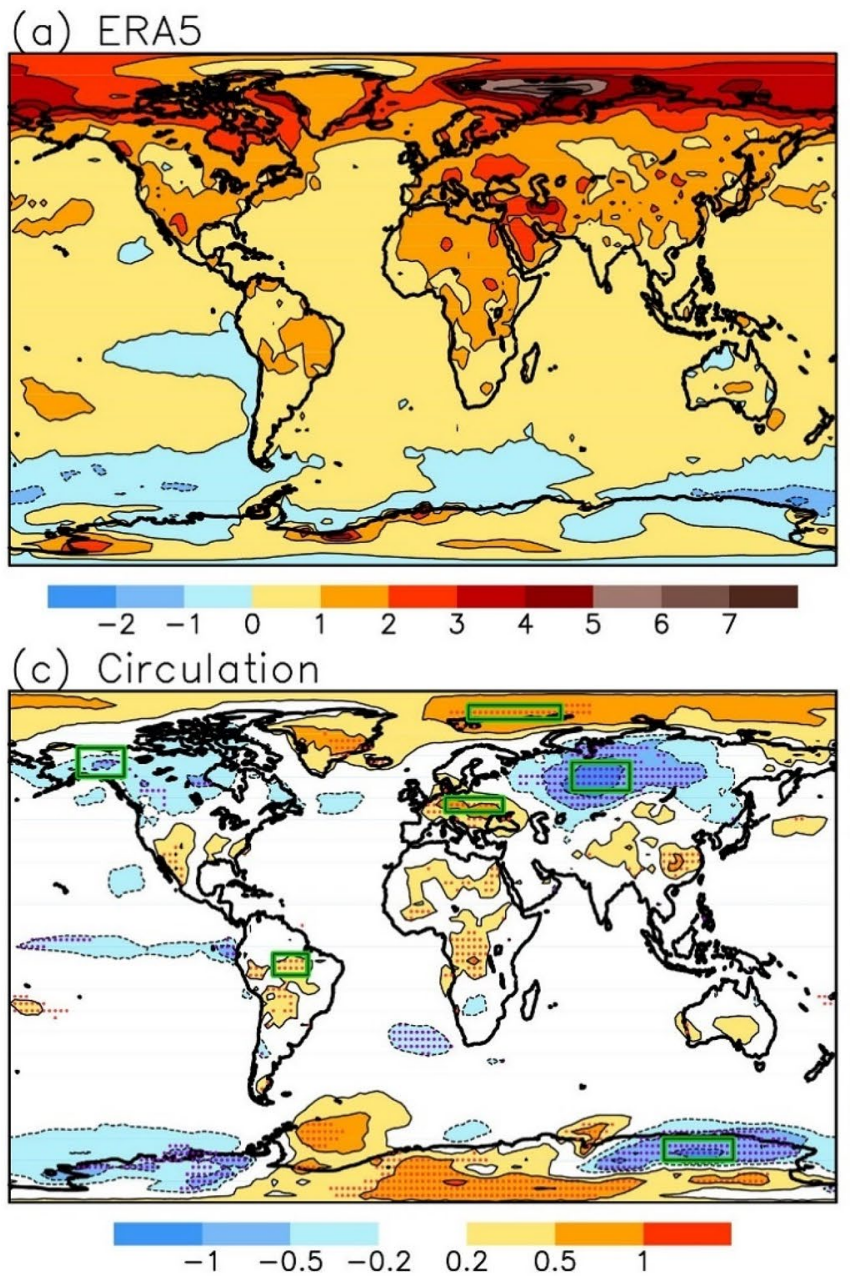

Fig. 2 Annual mean temperature trends in years $1979-2018\left({ }^{\circ} \mathrm{C}\right.$ $\left(39\right.$ year $^{-1}$ ). a ERA5, b CMIP5 multi-model mean, c contribution of circulation change to the ERA5 trend, $\mathbf{d}$ Difference a minus $\mathbf{c}$. In

\section{Annual and seasonal mean temperature changes}

The 1979-2018 linear trend in annual mean temperature in ERA5 is shown in Fig. 2a. The reanalysis indicates a global mean warming of $0.7{ }^{\circ} \mathrm{C}$ during this period, but with local trends ranging from a cooling of $2{ }^{\circ} \mathrm{C}$ (off the coast of East Antarctica) to a warming of $7{ }^{\circ} \mathrm{C}$ (north of Novaya Zemlya). The distribution of trends in ERA5 has a high pattern correlation $(r=0.81)$ with the CMIP5 multimodel mean (Fig. 2b). However, the global mean warming is larger for the latter $\left(0.9^{\circ} \mathrm{C}\right)$, consistent with earlier studies that have found CMIP5 simulations to overestimate the warming in the past few decades (Rosenblum and Eisenman 2017; Power et al. 2017). More importantly, the spatial variability is much larger for ERA5. The contrast between the Northern and the Southern Hemisphere is

\section{(b) CMIP5}
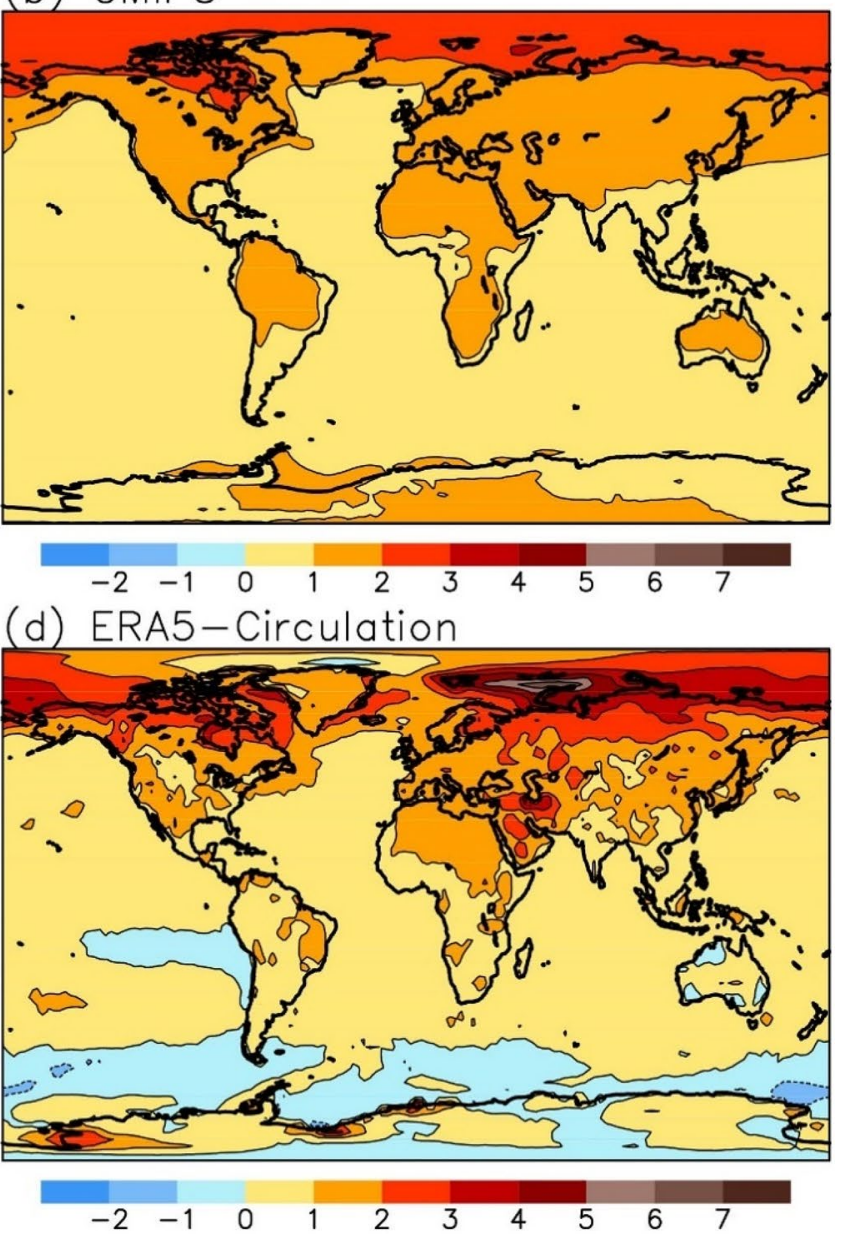

c, the stippling indicates areas where the contribution of circulation change is significant in the sense detailed in Sect. 2, and the green rectangles outline the areas studied in Sect. 5 
more pronounced in ERA5 and there is much more smallscale variation, although some of the local features might be due to inhomogeneity in the underlying observations.

The circulation-related annual mean temperature trends in ERA5 are relatively small in most areas (Fig. 2c). Exceptions include circulation-related cooling of $1{ }^{\circ} \mathrm{C}$ in western Siberia and at the East Antarctic coast south of Australia, as well as circulation-related warming exceeding $0.5^{\circ} \mathrm{C}$ (e.g.) in central-to-eastern Europe, southeastern China, in the interior of Antarctica, and the Eurasian sector of the Arctic Ocean. These circulation-related changes explain some of the regional details in the ERA5 trends, including the local minimum of warming in western Siberia (compare Fig. 2a with the residual trends in Fig. 2d). Overall, however, the pattern of the residual trends is similar to the original ERA5 trends. Furthermore, the annual mean differences to the CMIP5 multi-model mean are only marginally reduced in a statistical sense (Sect. 6). With the caveat that the trajectory method might not fully capture the effects of atmospheric circulation, this suggests that circulation changes have not been a dominant cause for the differences between the reanalyzed (or observed) and CMIP5 multi-model annual mean temperature trends.

Atmospheric circulation trends have had a larger impact on seasonal than annual mean temperature trends (Fig. 3). The circulation-related trends in DJF range from a cooling of $3{ }^{\circ} \mathrm{C}$ in western Siberia to a warming of $4{ }^{\circ} \mathrm{C}$ northeast of Spitsbergen in the Arctic Ocean (Fig. 3a). Weaker cooling covers much of northern Eurasia and weaker warming most of the Arctic Ocean. Weaker $\left(1^{\circ} \mathrm{C}\right)$ but significant circulation-related warming also occurred in Alaska and northwestern Canada. Circulation-related temperature changes in the Southern Hemisphere were generally smaller in this season.

The circulation-related trends in March-April-May (MAM, Fig. 3b) are remarkably different from those in DJF. Notable features in the Northern Hemisphere include cooling of Alaska and northern Canada, warming in southeastern United States, cooling in northern Europe and the European sector of the Arctic Ocean, and warming extending from central Asia northeast towards eastern Siberia and the East (a) December-January-February
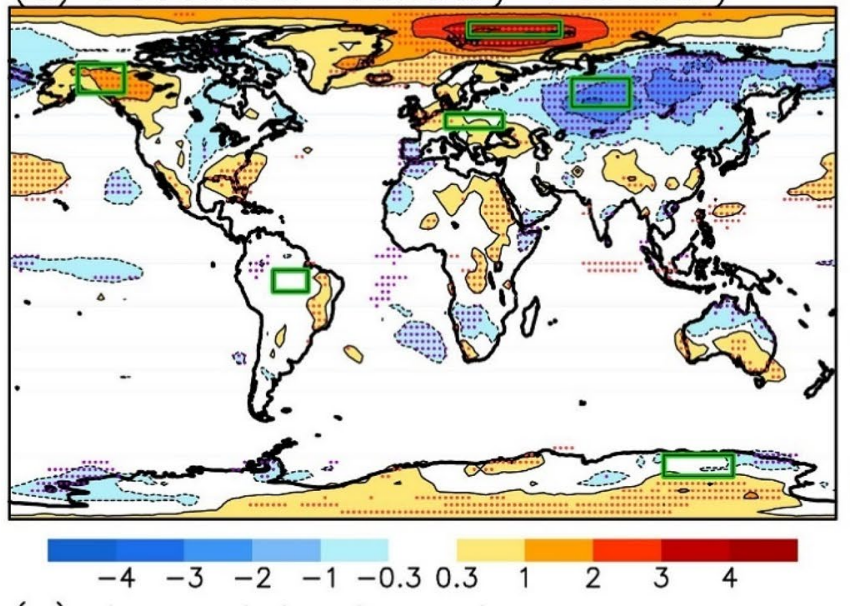

(c) June-July-August

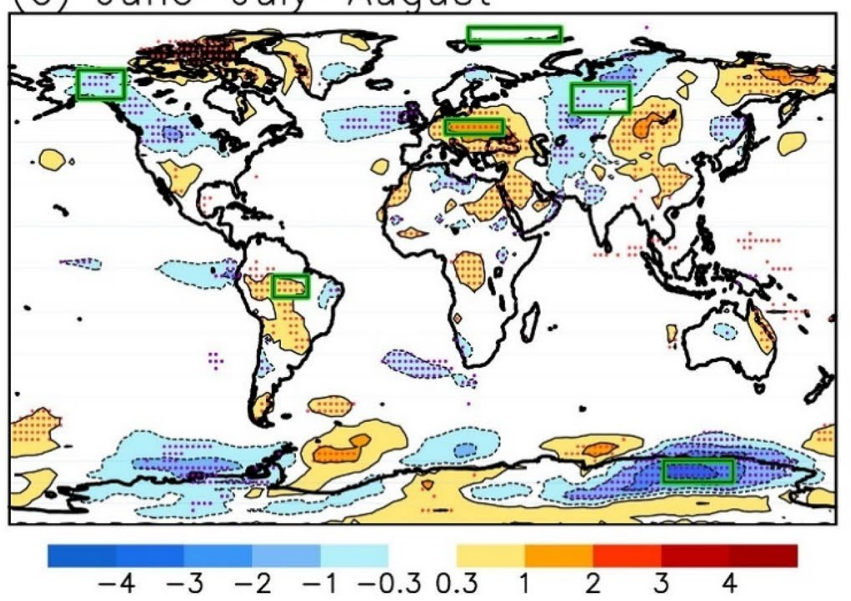

(b) March-April-May

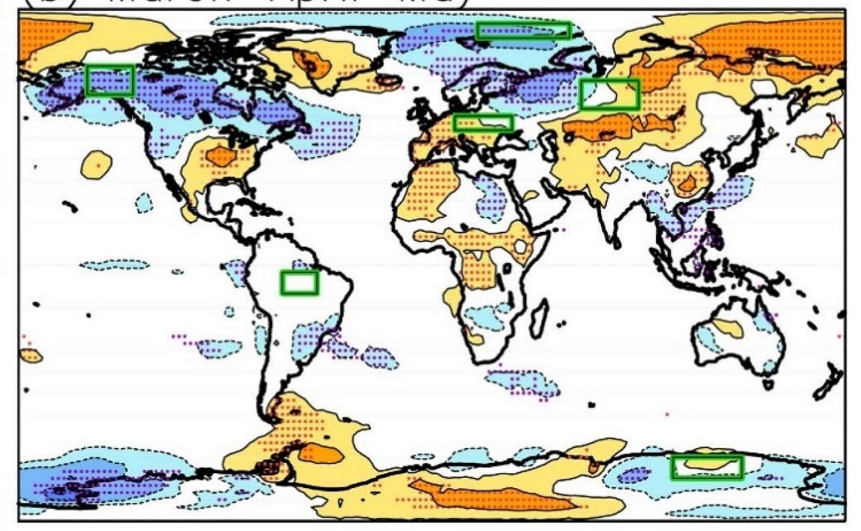

$\begin{array}{llllllllllll}-4 & -3 & -2 & -1 & -0.3 & 0.3 & 1 & 2 & 3 & 4\end{array}$

(d) September-October-November

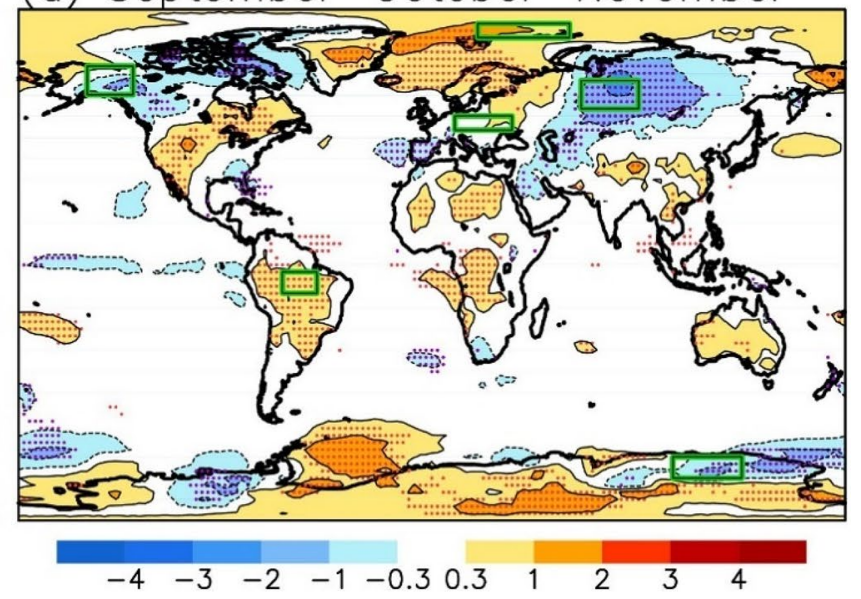

Fig. 3 As Fig. 2c, but for the contribution of circulation change to the ERA5 temperature trends in the standard three-month seasons 
Siberian and Chukchi Seas. Circulation-related cooling locally reached $2{ }^{\circ} \mathrm{C}$ in western West Antarctica, whereas warming of up to over $1{ }^{\circ} \mathrm{C}$ occurred in the interior of East Antarctica.

In June-July-August (JJA, Fig. 3c), a wave pattern with alternating patches of circulation-related warming and cooling is evident in Eurasia, with the strongest warming $\left(\sim 1^{\circ} \mathrm{C}\right)$ in central to eastern Europe and eastern Siberia and the most extensive area of cooling in central Asia and western Siberia. A band of slight cooling is also evident in northwestern North America. However, the largest circulation-related trend in this season is cooling of up to $3{ }^{\circ} \mathrm{C}$ over the Australian sector of East Antarctica.

Circulation-related cooling of up to $2{ }^{\circ} \mathrm{C}$ occurred in September-October-November (SON) in western to central Siberia (Fig. 3d), in broadly the same areas that also experienced strong cooling in winter (Fig. 3a). The circulationrelated warming over the northernmost North Atlantic and the European sector of the Arctic Ocean is also common with winter, although smaller in magnitude. However, in contrast to winter, circulation changes are found to have amplified the warming of autumns in the easternmost Siberia. The largest circulation-related trends in the Southern Hemisphere again occur over the Antarctica and the Southern Ocean.

The patterns of the circulation-related temperature trends have both notable similarities and striking differences between the four seasons. However, they are nearly uncorrelated in a statistical sense. As a quantitative measure, the global root-mean-square (rms) amplitudes of the local circulation-related 39-year temperature trends in the four seasons were $0.44{ }^{\circ} \mathrm{C}, 0.39^{\circ} \mathrm{C}, 0.34^{\circ} \mathrm{C}$ and $0.35^{\circ} \mathrm{C}$, beginning from DJF. Assuming independence between the seasons, in which case the four seasonal trends would be additive in a quadratic sense, would suggest an annual rms amplitude of $0.19^{\circ} \mathrm{C}$. This is just $10 \%$ below the actual rms value $\left(0.21{ }^{\circ} \mathrm{C}\right)$ of the annually averaged circulation-related trends.

\section{Case studies}

In this section, we study in more detail the monthly mean temperature trends in six areas (see Table 1 and the green rectangles in Figs. 2c, 3), which all exhibit pronounced annual and/or seasonal mean circulation-related temperature trends. Global maps of the circulation-related monthly mean temperature trends are given in Fig. S9.

For each of the six areas, a similar figure with four panels is given (Figs. 4, 6, 8, 10, 12,14). The first panel quantifies the skill of the regression method in terms of the explained variance, and the second panel shows the ERA5 and the circulation-related monthly mean temperature trends. The residual trends are given in the third panel. Finally, the last
Table 1 The areas studied in Sect. 5

\begin{tabular}{ll}
\hline Area & Coordinates \\
\hline Arctic Ocean & $80^{\circ}-85^{\circ} \mathrm{N}, 20^{\circ}-60^{\circ} \mathrm{E}$ \\
West Siberia & $55^{\circ}-65^{\circ} \mathrm{N}, 65^{\circ}-90^{\circ} \mathrm{E}$ \\
Alaska-Yukon & $60^{\circ}-70^{\circ} \mathrm{N}, 130^{\circ}-150^{\circ} \mathrm{W}$ \\
Central Europe & $47.5^{\circ}-52.5^{\circ} \mathrm{N}, 10^{\circ}-35^{\circ} \mathrm{E}$ \\
East Antarctica & $67.5^{\circ}-75^{\circ} \mathrm{S}, 105^{\circ}-135^{\circ} \mathrm{E}$ \\
Amazonia & $2.5^{\circ}-10^{\circ} \mathrm{S}, 50^{\circ}-65^{\circ} \mathrm{W}$ \\
\hline
\end{tabular}

panel compares the ERA5 trends and the residual trends with the trends in the CMIP5 models. In addition, maps that illustrate the change in atmospheric circulation and in the origin of trajectories in one or two interesting months are shown for each of the five extratropical areas (Figs. 5, 7, $9,11,13)$. In most cases, these are for $775 \mathrm{hPa}$ which is the middlemost end level used in the trajectory calculations. For East Antarctica (Sect. 5.5), where the average surface pressure is less than $700 \mathrm{hPa}$, the $625 \mathrm{hPa}$ level is chosen. For Amazonia, where the circulation-related temperature anomalies appear to primarily reflect the effect of vertical motion on cloudiness, a different way of illustration is used (Fig. 15).

Global maps of monthly $775 \mathrm{hPa}$ circulation trends are provided in Fig. S10. Trajectory frequency trend maps for each of the six case study areas for all 12 months of the year are given in Figs. S11-S16, and the corresponding 1979-to2018 monthly time series of the ERA5, circulation-related and residual temperature anomalies are shown in Figs. S17-S22.

\subsection{Arctic Ocean}

Despite the strong direct impact of sea ice conditions, the trajectory-based regression explains most of the interannual temperature variations over the European sector of the Arctic Ocean $\left(80^{\circ}-85^{\circ} \mathrm{N}, 20^{\circ}-60^{\circ} \mathrm{E}\right)$ in the winter half-year (Fig. 4a). In summer, the skill is negligible, but the temperature variations are very small due to the presence of melting ice. The area has warmed rapidly in recent decades, particularly in winter. The annual average 39 -year trend in ERA5 is $4.2^{\circ} \mathrm{C}$, but the monthly trends vary from zero in July to over $9{ }^{\circ} \mathrm{C}$ in January (Fig. 4b). The CMIP5 multimodel mean warming is $2.6^{\circ} \mathrm{C}$ in the annual mean, peaking at $5{ }^{\circ} \mathrm{C}$ in October-November but decreasing to $3{ }^{\circ} \mathrm{C}$ by January (Fig. 4d).

More than half of the mid-winter trend difference between ERA5 and the CMIP5 multi-model mean is explained by atmospheric circulation, which has amplified the warming by $3-4{ }^{\circ} \mathrm{C}$ in December, January and February (Fig. $4 b$, d). Even so, the residual warming in these months exceeds the CMIP5 average, likely reflecting the tendency of the models 


\section{Arctic Ocean}

Lat $=80$ to $85 ;$ Lon $=20$ to 60
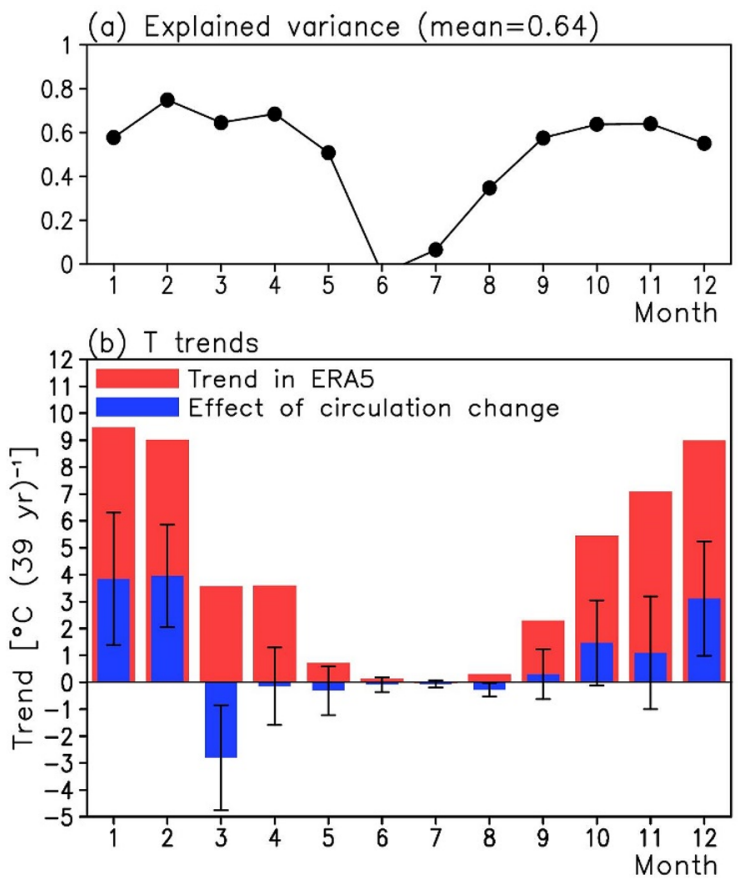

Fig. 4 Temperature trend diagnostics for the Arctic Ocean area. a Detrended variance explained by the trajectory-based regression. b 1979-to-2018 temperature trends in ERA5 (red) and the contribution of atmospheric circulation (blue). c Residual trends not explained by atmospheric circulation. d Comparison of the ERA5 trends (red

to underestimate the recent sea ice decrease (Rosenblum and Eisenman 2017). In March, atmospheric circulation has reduced the warming, and the difference from the CMIP5 multi-model mean is therefore larger for the residual than for the original ERA5 trend.

To illustrate the circulation changes that have affected the Arctic area, January and March are chosen for a closer study in Fig. 5. The left panels show the trends in $775 \mathrm{hPa}$ height and wind fields together with the climatological temperature distribution, while the right panels depict the 40-year mean density and density trends for 96 -h trajectories ending at $775 \mathrm{hPa}$ in the centre or the region $\left(82.5^{\circ} \mathrm{N}, 40^{\circ} \mathrm{E}\right)$. Note that this is just one of the 49 trajectory duration-end level combinations used for estimating the circulation-related temperature variability, and changes in vertical motion along the trajectories are not visible in this presentation. Nonetheless, the differences between the 2 months are apparent. The trend maps in Fig. 5a show an anomalous high centred near Novaya Zemlya, together with increased southerly (westerly) flow to the west (north) of this high. Associated with this is increased frequency of trajectories arriving from the relatively mild North Atlantic_-European sector, together with reduced frequency of trajectories arriving from the eastern Arctic Ocean and northern Siberia (Fig. 5b). Conversely, the
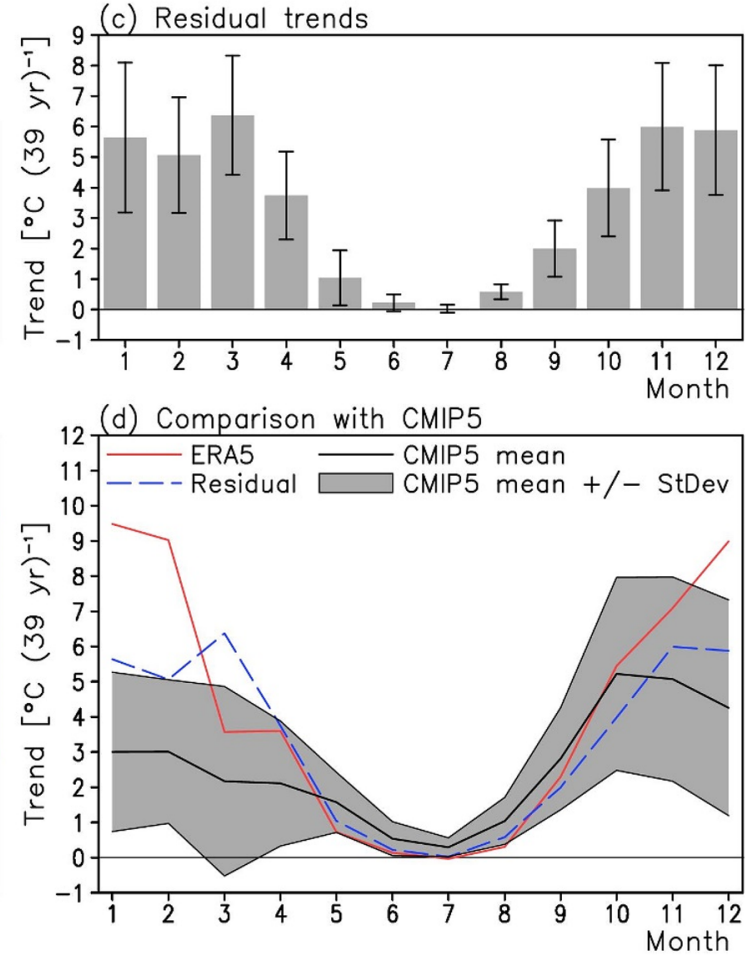

solid) and the residual trends (blue dashed) with temperature trends in the CMIP5 simulations (solid black for multi-model mean, shading for mean \pm standard deviation). The error bars in $\mathbf{b}$, $\mathbf{c}$ indicate the $5-95 \%$ uncertainty range in the circulation-related trend and the residual trend based on interannual variability

circulation trends in March feature an anomalous low to the south of Novaya Zemlya and increased easterly flow over the western Arctic Ocean (Fig. 5c). Consistent with this, the trends in the trajectory distribution are broadly the opposite to those in January, although smaller in magnitude (Fig. 5d).

\subsection{West Siberia}

Interannual temperature variations in West Siberia $\left(55^{\circ}-65^{\circ}\right.$ $\mathrm{N}, 65^{\circ}-90^{\circ} \mathrm{E}$ ) are explained remarkably well by the trajectory-based regression model, with $E=86 \%$ as a 12 -month variance-weighted mean (Fig. 6a). The ERA5 temperature trends in 1979-2018 vary from a cooling of nearly $2{ }^{\circ} \mathrm{C}$ in January to a warming of over $4{ }^{\circ} \mathrm{C}$ in April, with an annual mean warming of $1.1^{\circ} \mathrm{C}$ (Fig. 6b). Atmospheric circulation has amplified the warming in March, April and June but counteracted it in all other months. This circulation-related cooling has been particularly pronounced from November to January, but it amounts to $1.1{ }^{\circ} \mathrm{C}$ even in the annual mean. This yields an annual mean residual warming of $2.2^{\circ} \mathrm{C}$ that is twice the ERA5 temperature trend (Fig. $6 \mathrm{c}$ ). The residual trends also exhibit a much smoother seasonal cycle than the actual temperature trends, except for a relatively sharp maximum in November. It is tempting to connect this November 
(a) January, circulation

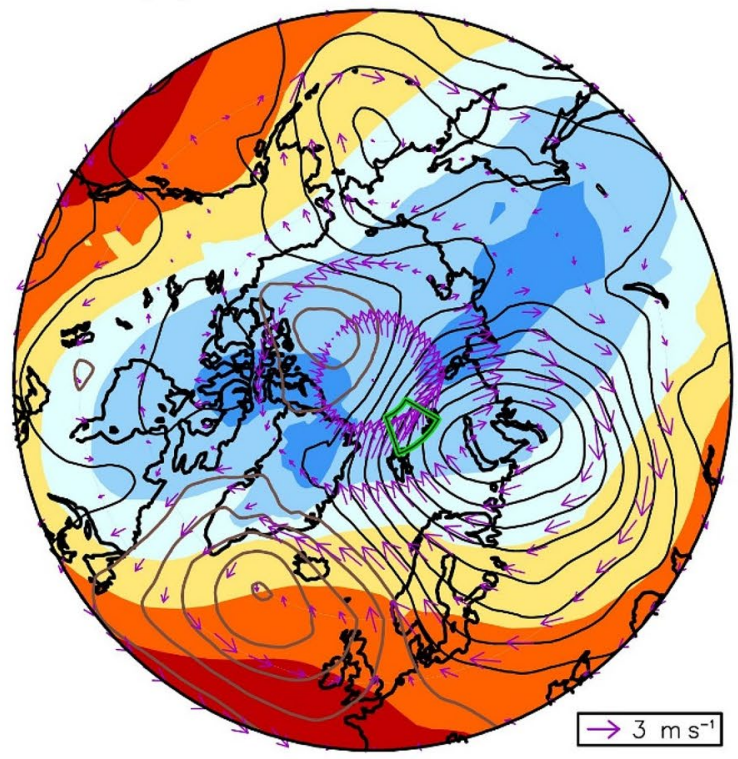

(c) March, circulation

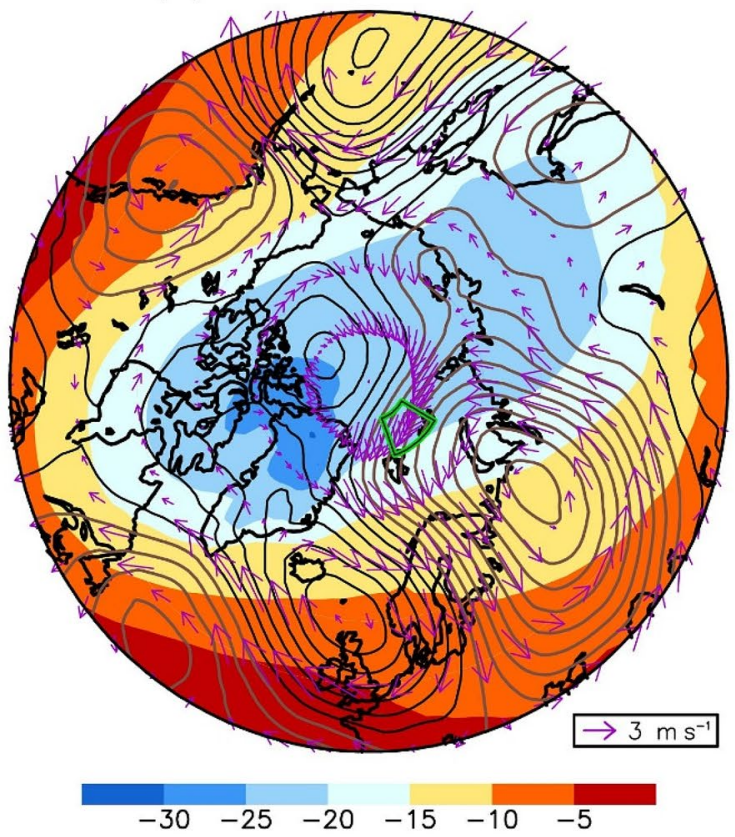

Fig. 5 a 40-year January means of $775 \mathrm{hPa}$ temperature (shading, colour bar in ${ }^{\circ} \mathrm{C}$ ) together with 39 -year trends in $775 \mathrm{hPa}$ height (contours) and wind (vectors). b 40-year January mean density of 96-h trajectories ending at $775 \mathrm{hPa}$ at the point $\left(82.5^{\circ} \mathrm{N}, 40^{\circ} \mathrm{E}\right.$; purple star) (contour interval $1 \times 10^{-6} \% \mathrm{~km}^{-2}$ ) and 39 -year trends in this (shading, colour bar in $10^{-6} \% \mathrm{~km}^{-2}\left(39\right.$ year) $\left.{ }^{-1}\right)$. c, d As a, b but for

peak in residual warming to the recent decrease in the Arctic Ocean autumn ice cover, although confirmation of this would require further investigation.

The residual trends in West Siberia are generally closer to the CMIP5 multi-model mean than the original ERA5 trends (b) January, trajectories

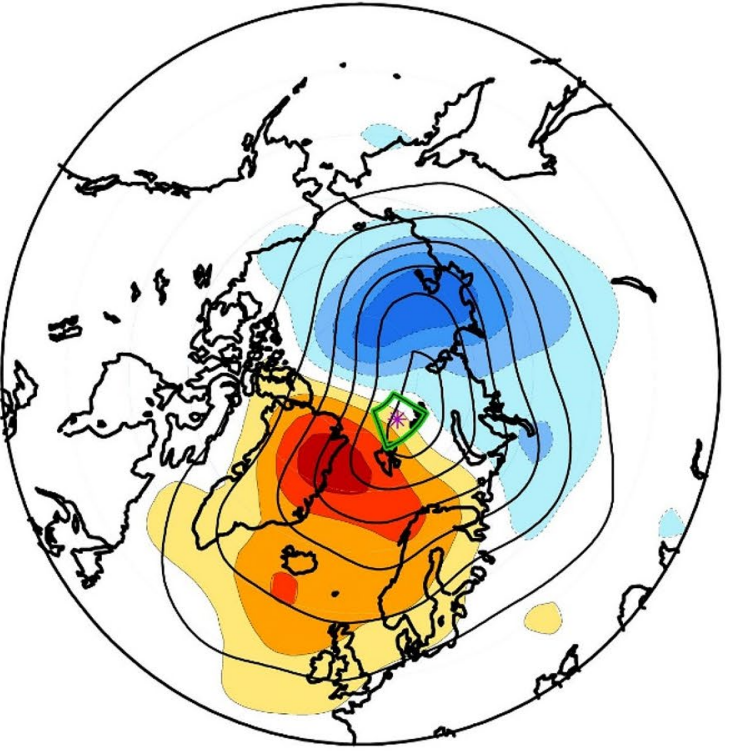

(d) March, trajectories

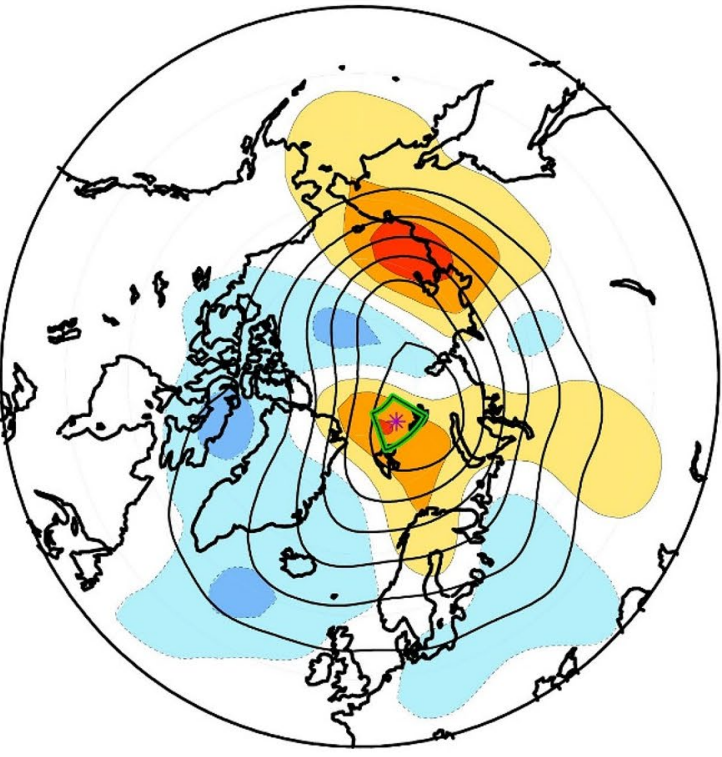

$-4.5-3.5-2.5-1.5-0.5 \quad 0.5 \quad 1.5 \quad 2.5 \quad 3.5 \quad 4.5$

March. The contour interval for the height trends in $\mathbf{a}$ and $\mathbf{c}$ is $10 \mathrm{~m}$ (39 year) ${ }^{-1}$, with the first black (brown) contour indicating a trend that is $5 \mathrm{~m} \mathrm{(39}$ year) $)^{-1}$ above (below) the global average. Gaussian smoothing ( $\lambda=500 \mathrm{~km}$ in Eq. (1) of Räisänen and Ylhäisi 2011) was applied to the trajectory densities. The green rectangle shows the area $\left(80^{\circ}-85^{\circ} \mathrm{N}, 20^{\circ}-60^{\circ} \mathrm{E}\right)$

are, although they exceed the CMIP5 mean warming in most months of the year (Fig. 6d).

The strongest circulation-related cooling in West Siberia occurred in November and January. The trend maps for both months reveal an increasingly easterly or 
West Siberia

Lat $=55$ to $65 ;$ Lon $=65$ to 90
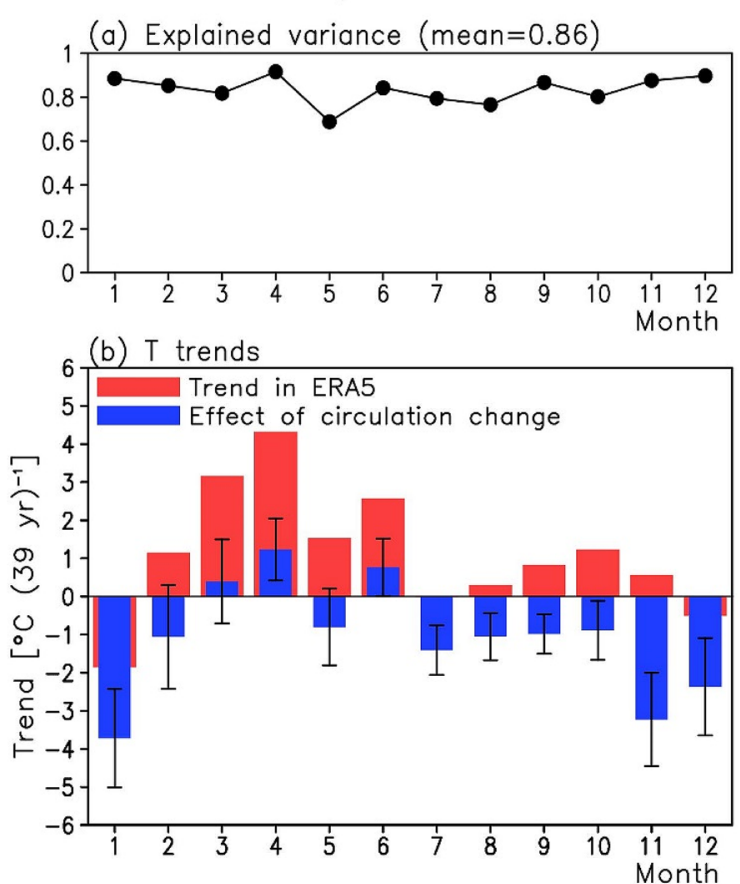
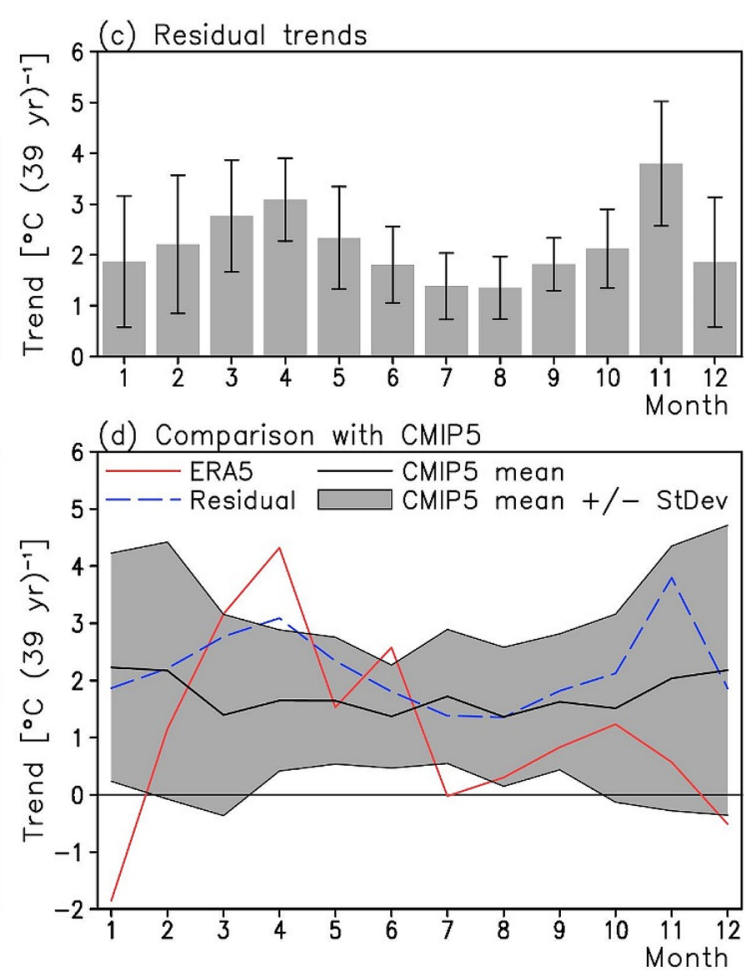

Fig. 6 As Fig. 4 but for West Siberia

(a) November, circulation

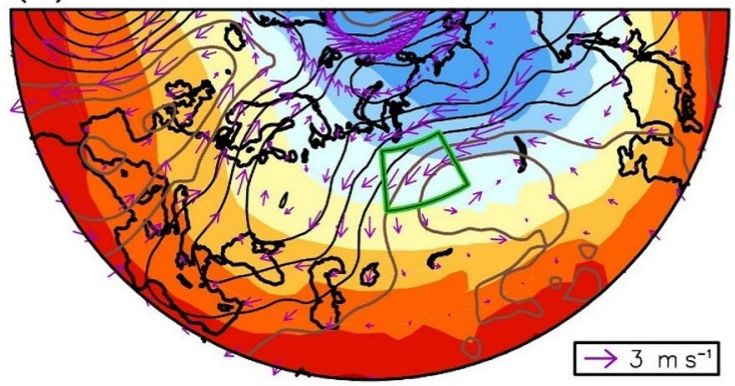

(c) January, circulation

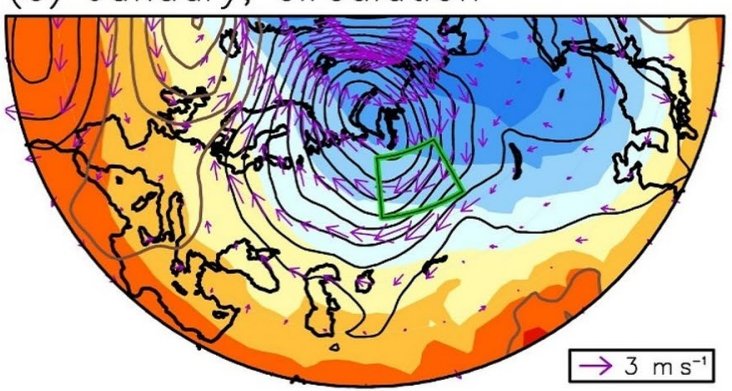

$$
\begin{array}{llllllll}
-25 & -20 & -15 & -10 & -5 & 0 & 5 & 10
\end{array}
$$

Fig. 7 a 40-year November means of $775 \mathrm{hPa}$ temperature together with 39-year trends in $775 \mathrm{hPa}$ height and wind. b 40-year November mean density of $96-\mathrm{h}$ trajectories ending at $775 \mathrm{hPa}$ at the point $\left(60^{\circ}\right.$ (b) November, trajectories

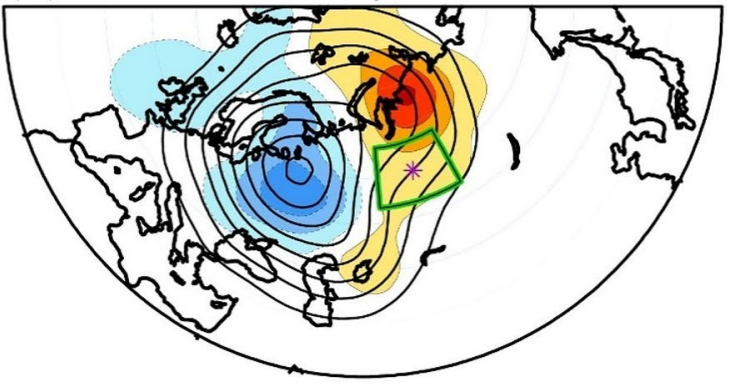

(d) January, trajectories

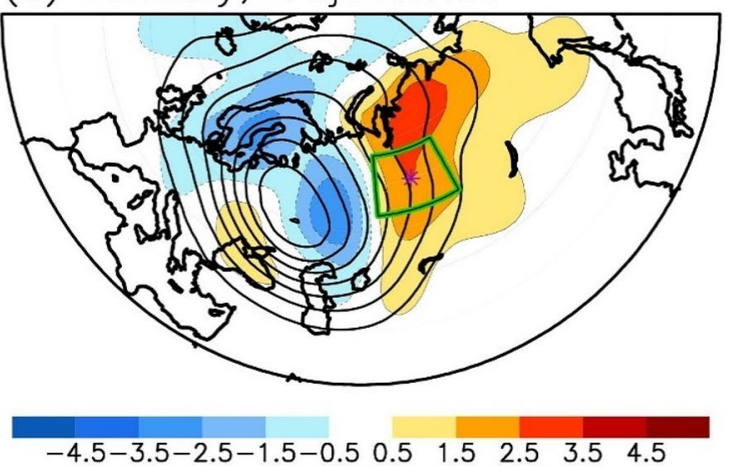

$\mathrm{N}, 77.5^{\circ} \mathrm{E}$; purple star) and 39-year trends in this. c, $\mathbf{d}$ as $\mathbf{a}, \mathbf{b}$ but for January. The green rectangle shows the area $\left(55^{\circ}-65^{\circ} \mathrm{N}, 65^{\circ}-90^{\circ} \mathrm{E}\right)$. See the caption of Fig. 5 for additional details 


\section{Alaska-Yukon}

Lat $=60$ to 70 ; Lon $=-150$ to -130
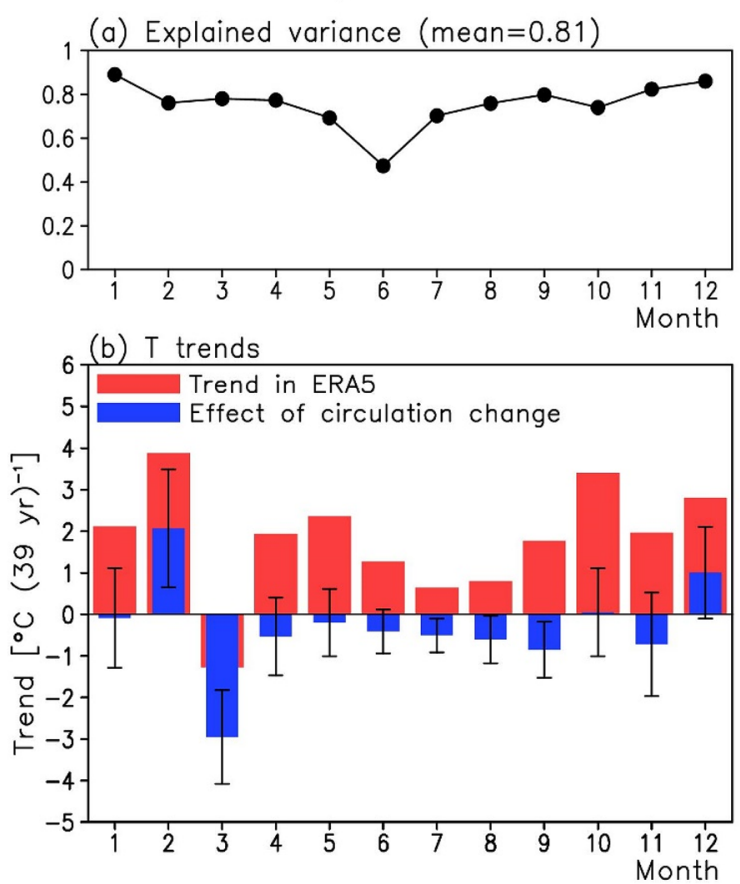
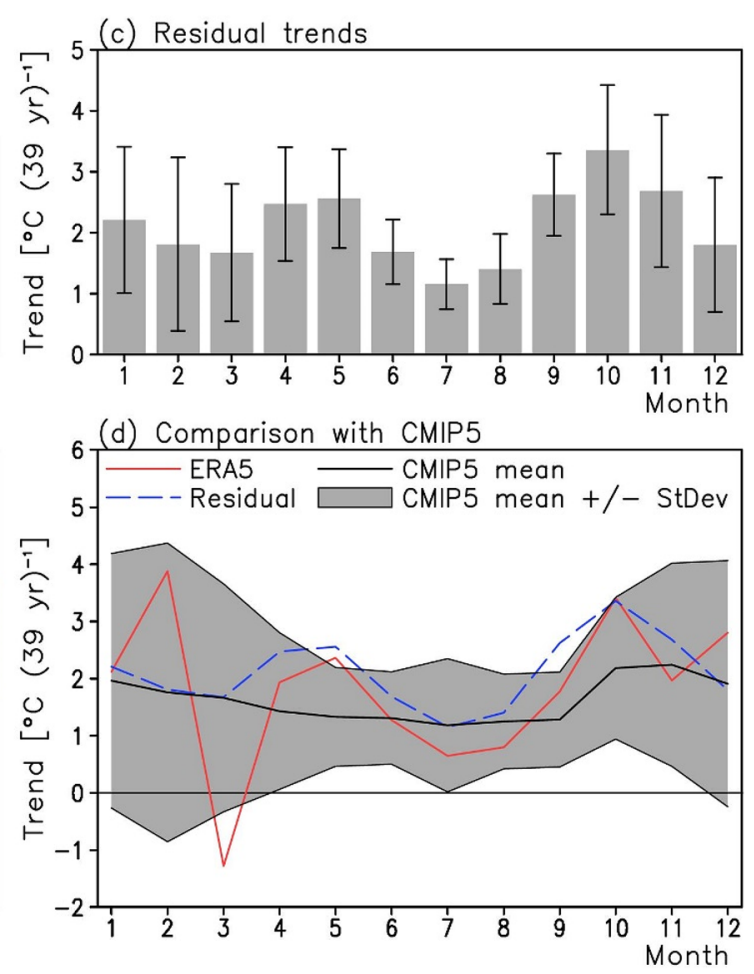

Fig. 8 As Fig. 4 but for Alaska-Yukon

(a) February, circulation

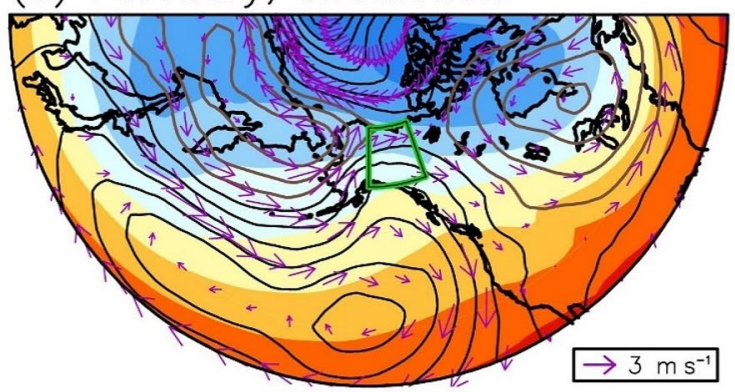

(c) March, circulation

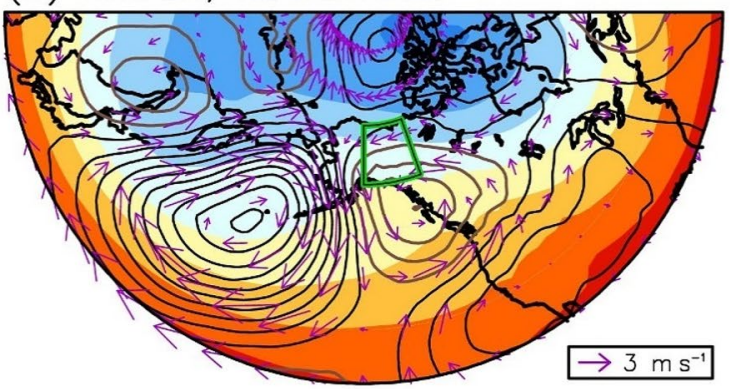

$\begin{array}{lllllll}-25 & -20 & -15 & -10 & -5 & 0 & 5\end{array}$

Fig. 9 a 40-year February means of $775 \mathrm{hPa}$ temperature together with 39-year trends in $775 \mathrm{hPa}$ height and wind. b 40-year February mean density of $96-\mathrm{h}$ trajectories ending at $775 \mathrm{hPa}$ at the point $\left(65^{\circ}\right.$ (b) February, trajectories

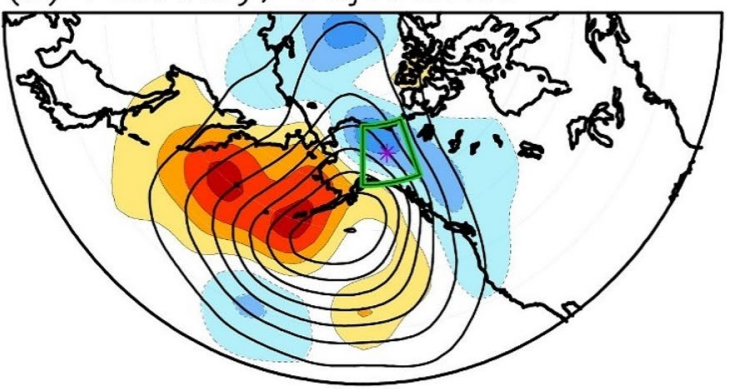

(d) March, trajectories

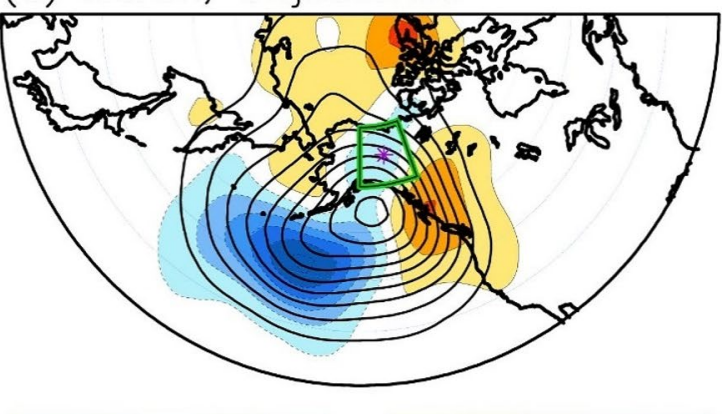

$-4.5-3.5-2.5-1.5-0.5 \quad 0.5 \quad 1.5 \quad 2.5 \quad 3.5 \quad 4.5$

$\mathrm{N}, 140^{\circ} \mathrm{W}$; purple star) and 39 -year trends in this. c, $\mathbf{d}$ as $\mathbf{a}, \mathbf{b}$ but for March. The green rectangle shows the area $\left(60^{\circ}-70^{\circ} \mathrm{N}, 130^{\circ}-150^{\circ}\right.$ W). See the caption of Fig. 5 for additional details 
Central Europe

Lat $=47.5$ to 52.5 ; Lon $=10$ to 35
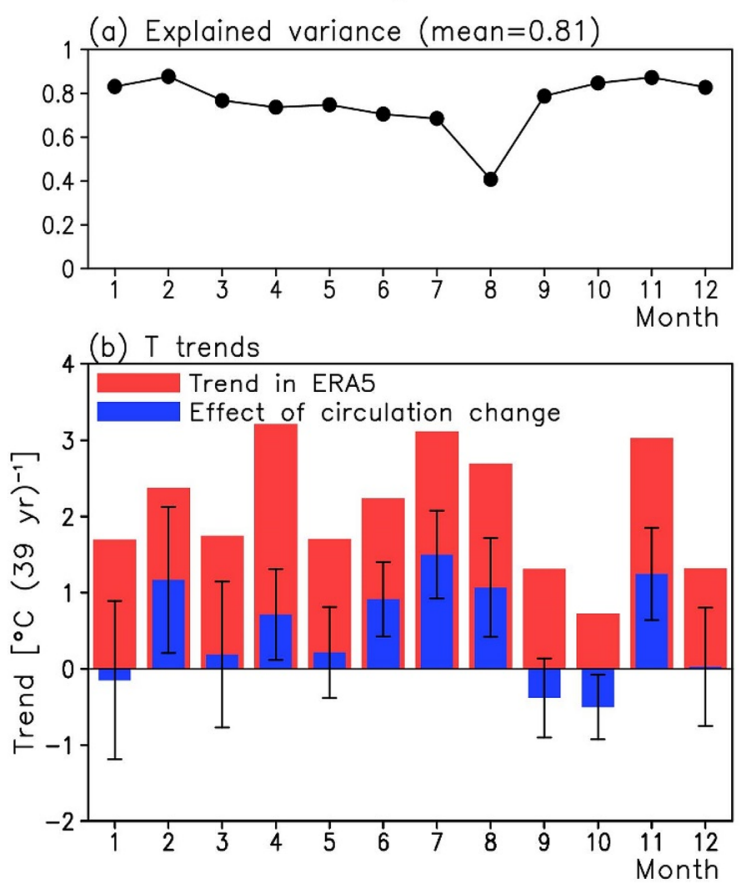
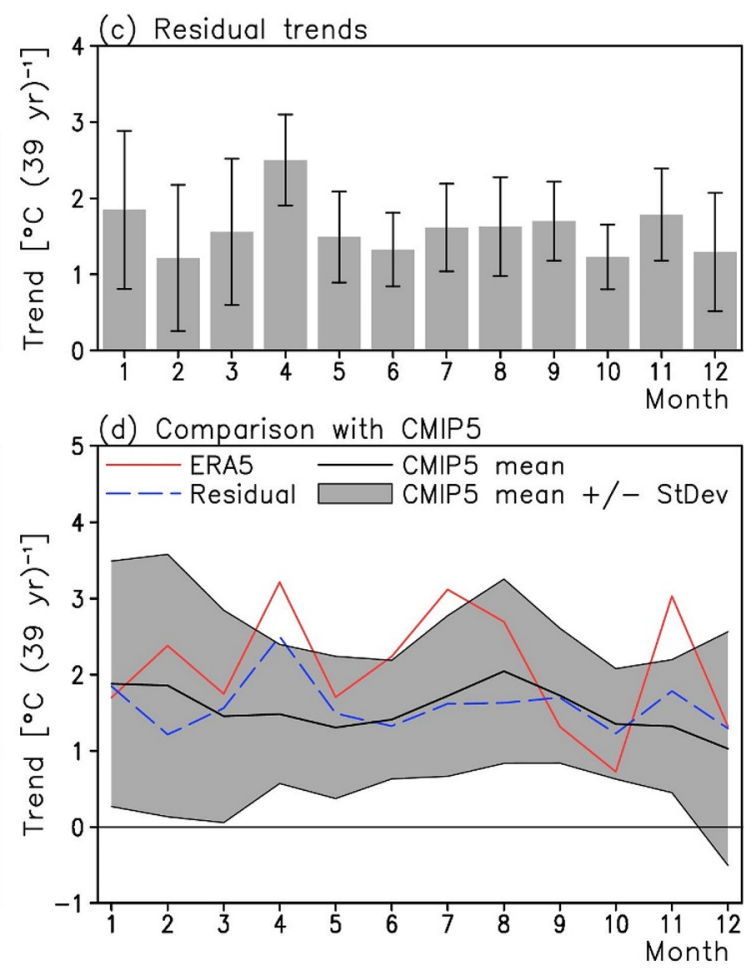

Fig. 10 As Fig. 4 but for Central Europe

(a) July, circulation

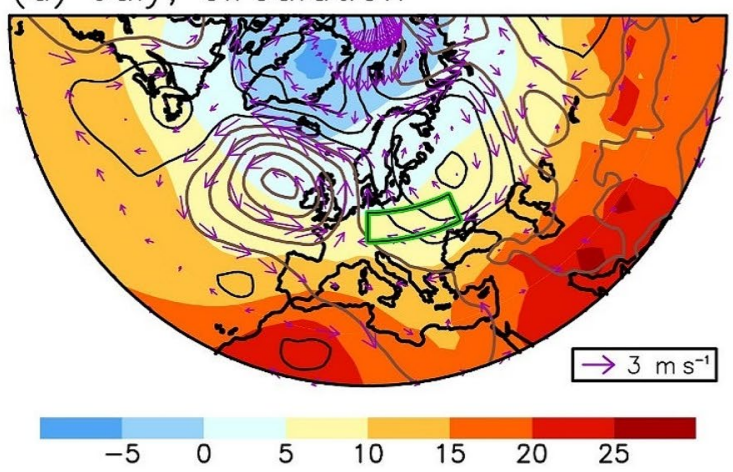

Fig. 11 a 40-year July means of $775 \mathrm{hPa}$ temperature together with 39 -year trends in $775 \mathrm{hPa}$ height and wind. b 40-year July mean density of $96-\mathrm{h}$ trajectories ending at $775 \mathrm{hPa}$ at the point $\left(50^{\circ} \mathrm{N}, 22.5^{\circ}\right.$

northeasterly flow type in the lower troposphere (Fig. 7a, c), with a decreasing fraction of trajectories arriving from Europe and the Atlantic Ocean and an increasing fraction from further north and east in Siberia (Fig. 7b, d). See Figs. S10 and S12 for the trends in circulation and trajectory frequencies in the other months of the year. (b) July, trajectories

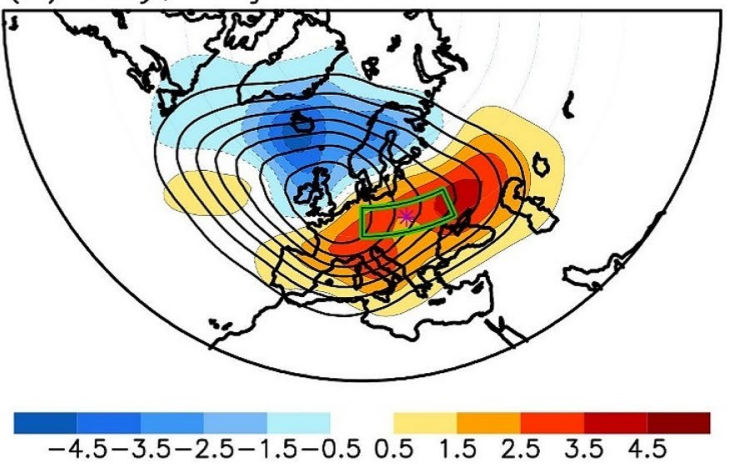

E; purple star) and 39-year trends in this. The green rectangle shows the area $\left(47.5^{\circ}-52.5^{\circ} \mathrm{N}, 10^{\circ}-35^{\circ} \mathrm{E}\right)$. See the caption of Fig. 5 for additional details

\subsection{Alaska-Yukon}

In the area bordering Alaska and Yukon $\left(60^{\circ}-70^{\circ} \mathrm{N}\right.$, $\left.130^{\circ}-150^{\circ} \mathrm{W}\right), 69-89 \%$ of the detrended temperature variability is explained by the trajectory-based model in all months except for June (Fig. 8a). The annual mean 


\section{East Antarctica}

Lat $=-75$ to $-67.5 ;$ Lon $=105$ to 135
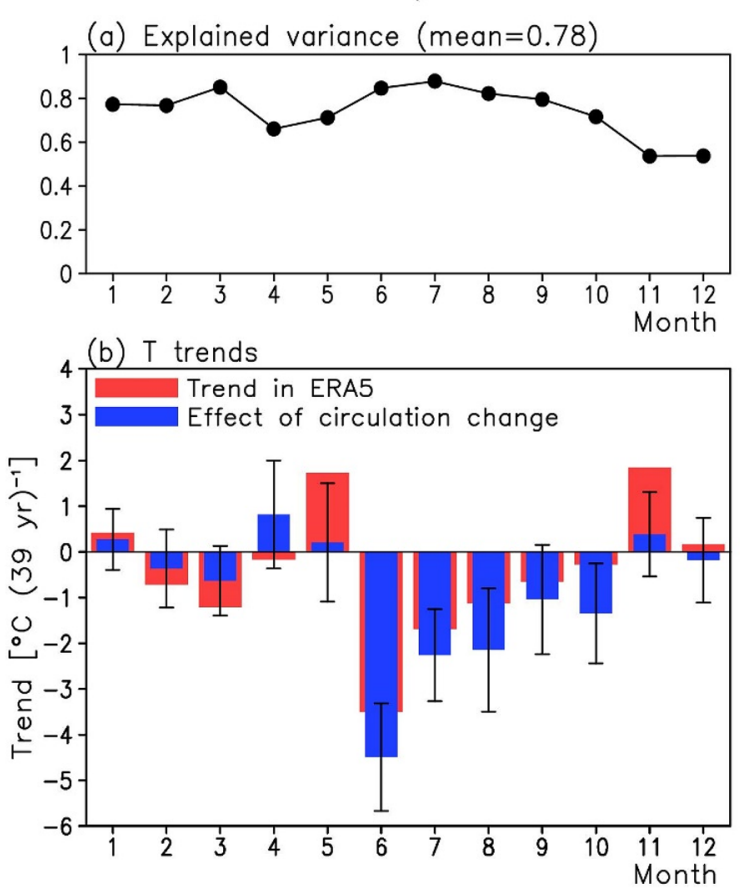
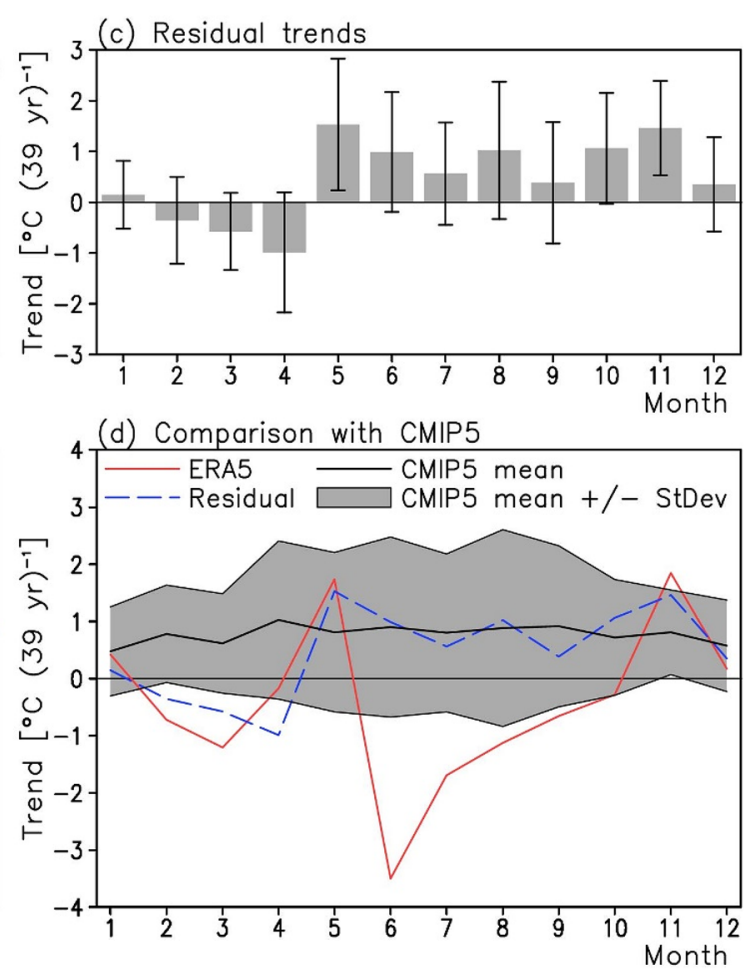

Fig. 12 As Fig. 4 but for East Antarctica

(a) June, circulation

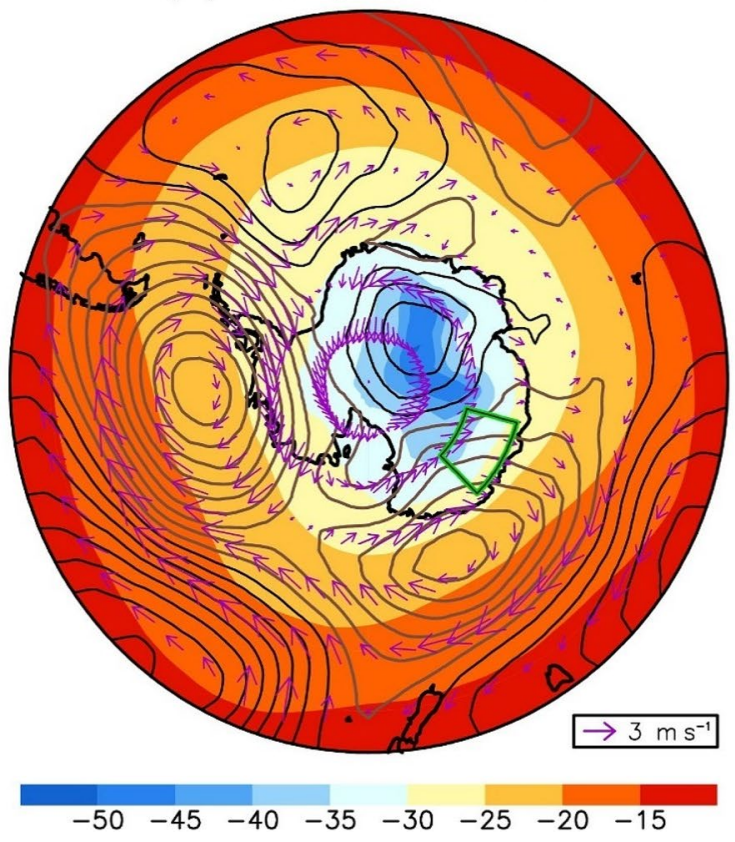

Fig. 13 a 40-year June means of $625 \mathrm{hPa}$ temperature together with 39 -year trends in $625 \mathrm{hPa}$ height and wind. b 40-year June mean density of $96-\mathrm{h}$ trajectories ending at $625 \mathrm{hPa}$ at the point $\left(72.5^{\circ} \mathrm{S}, 120^{\circ}\right.$ (b) June, trajectories

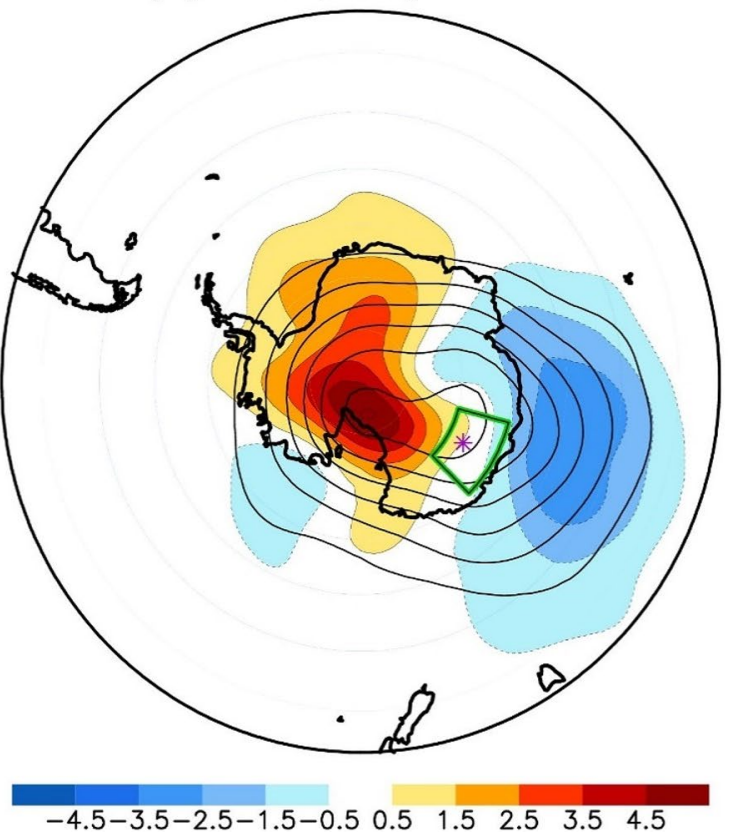

E; purple star) and 39-year trends in this. The green rectangle shows the area $\left(67.5^{\circ}-75^{\circ} \mathrm{S}, 105^{\circ}-135^{\circ} \mathrm{E}\right)$. See the caption of Fig. 5 for additional details 

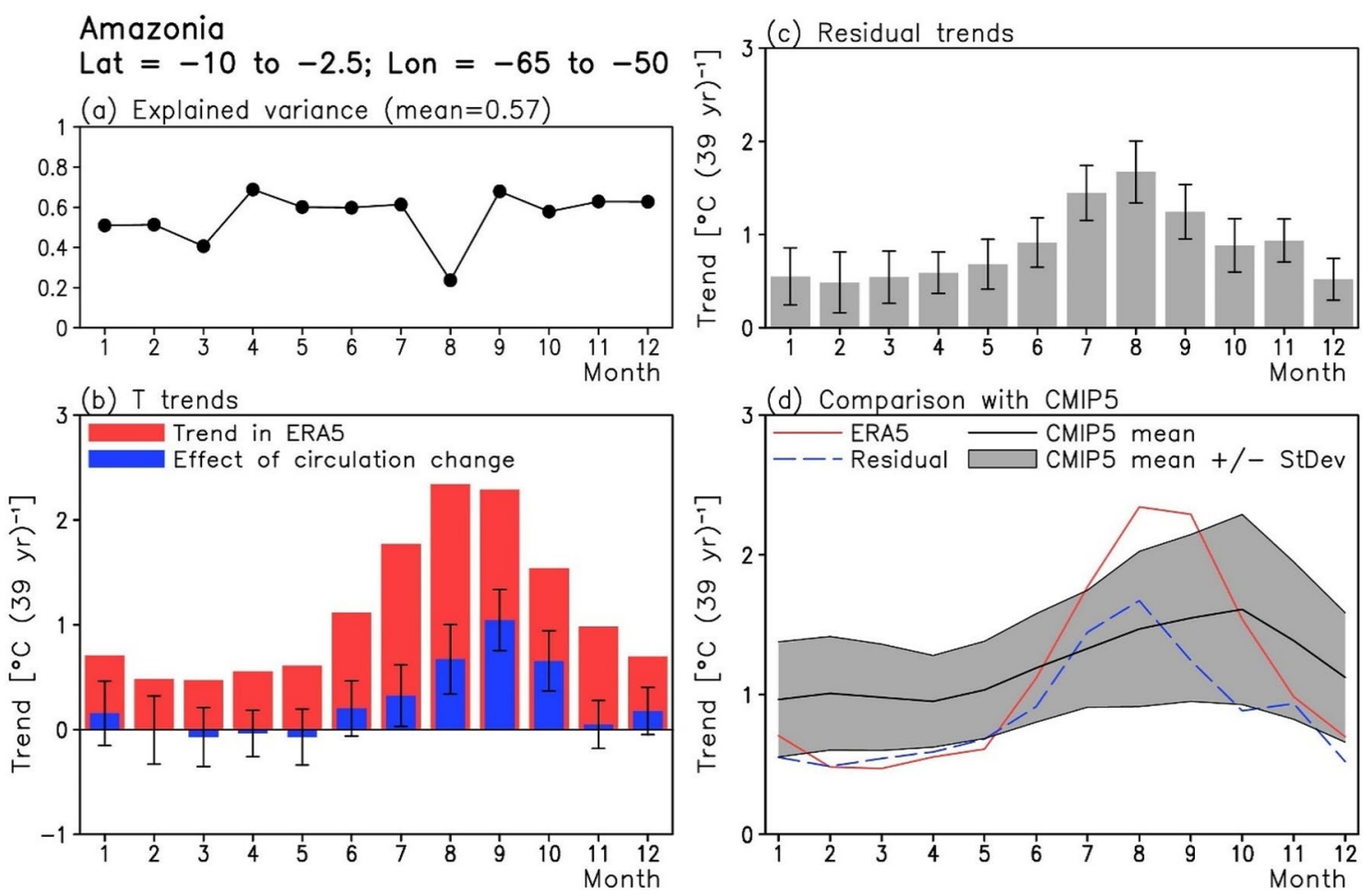

Fig. 14 As Fig. 4 but for Amazonia
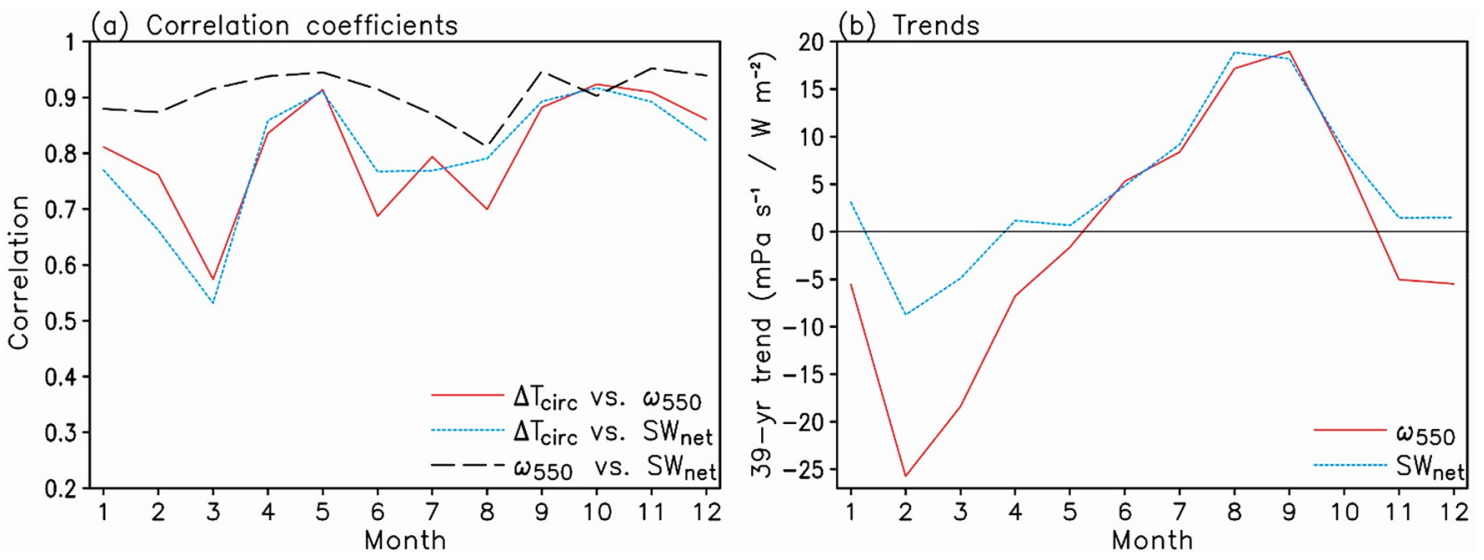

Fig. 15 a Correlation of area mean detrended circulation-related temperature anomalies in Amazonia $\left(2.5^{\circ}-10^{\circ} \mathrm{S}, 50^{\circ}-65^{\circ} \mathrm{W}\right)$ with $\omega(550 \mathrm{hPa})(\mathrm{red})$ and surface net solar radiation (blue), and the corre-

temperature trend in ERA5 amounts to $1.8^{\circ} \mathrm{C}(39 \text { year })^{-1}$, despite slight circulation-related cooling of $0.3{ }^{\circ} \mathrm{C}$ $(39 \text { year })^{-1}$ (Fig. 8b). However, there is a remarkably abrupt switch between strong circulation-related warming in February and cooling in March. The trends in lower-tropospheric height and wind fields (Fig. 9a, c) and trajectories (Fig. 9b, d) suggest increasingly oceanic, westerly-to-southwesterly flow in February but increasingly continental easterly flow in March. Again, the residual trends exhibit a smoother

lation between $\omega(550 \mathrm{hPa})$ and net solar radiation (black). b 1979-to2018 linear trends of $\omega(550 \mathrm{hPa})$ (red, in $\left.10^{-3} \mathrm{~Pa} \mathrm{~s}^{-1}(39 \text { year })^{-1}\right)$ and net solar radiation (blue, in $\left.\mathrm{W} \mathrm{m}^{-2}(39 \text { year })^{-1}\right)$

seasonal cycle than the original ERA5 trends (Fig. 8c), and they agree generally better with the CMIP5 multi-model mean (Fig. 8d). In spring and autumn, however, the residual warming exceeds the CMIP5 average.

\subsection{Central Europe}

In Central Europe $\left(47.5^{\circ}-52.5^{\circ} \mathrm{N}, 10^{\circ}-35^{\circ} \mathrm{E}\right)$, the trajectory model only explains $41 \%$ of the detrended temperature 
variability in August, but $68-89 \%$ of the variability in all other months (Fig. 10a). In contrast to West Siberia and Alaska, circulation changes have mostly amplified the warming in this area, explaining $0.5^{\circ} \mathrm{C}$ of the annual mean ERA5 trend of $2.1{ }^{\circ} \mathrm{C}$ (39 year $)^{-1}$ (Fig. 10b). The circulationrelated warming is largest $\left(1.5^{\circ} \mathrm{C}\right)$ in July but also exceeds $1{ }^{\circ} \mathrm{C}$ in February, August and November. The best-estimate residual warming peaks at $2.5^{\circ} \mathrm{C}$ in April but varies in the narrow range of $1.2-1.8^{\circ} \mathrm{C}$ in all other months (Fig. 10c). Apart from the April peak, the residual trends are in close agreement with the CMIP5 multi-model mean (Fig. 10d), in contrast to the original ERA5 trends that substantially exceed this in several months of the year.

The nature of circulation trends in and near Central Europe varies from month to month (Figs. S10, S14). The largest circulation-related warming in July is associated with increasingly anticyclonic and southeasterly flow (Fig. 11). Regarding other causes of temperature trends, Scherrer and Begert (2019) showed that changes in sunshine duration have likely played a role at least in Switzerland, particularly by increasing the daily maximum temperatures since year 1980. Part of this increased sunshine duration may have been caused by reduced aerosol pollution. However, slight differences in the areas and periods used complicate direct comparison of Scherrer's and Begert's (2019) results with the trends in Fig. 10.

\subsection{East Antarctica}

Coastal East Antarctica $\left(67.5^{\circ}-75^{\circ} \mathrm{S}, 105^{\circ}-135^{\circ} \mathrm{E}\right)$ has a decreasing annual mean temperature trend of $-0.4{ }^{\circ} \mathrm{C}$ (39 year) ${ }^{-1}$ in ERA5 (Fig. 2a) but the trends in the individual months vary from a cooling of $3.5^{\circ} \mathrm{C}$ in June to a warming of $1.8{ }^{\circ} \mathrm{C}$ in November (Fig. 12b). A large part of this variation is explained by atmospheric circulation which has had, in particular, a strong cooling effect between June and October. The residual trends (Fig. 12c) therefore show more consistency from month to month, with slight warming from May to January. In these months, the best-estimate residual trends are relatively close to the CMIP5 multi-model mean (Fig. 12d). By contrast, the best-estimate residual trends in the early southern fall from February to April remain negative, and thus more than one intermodel standard deviation below the CMIP5 average. However, the residual trends in this area are relatively small compared with their uncertainty (Fig. 12c).

The largest circulation-related cooling in the coastal East Antarctica in June coincides with decreasing $625 \mathrm{hPa}$ geopotential height trends to the northeast of the area (Fig. 13a). This has resulted in increasingly southerly winds, with an increasing fraction of the trajectories entering the area from the interior of the continent rather than from the Southern Ocean (Fig. 13b). A decrease in the frequency of trajectories arriving from the Southern Ocean is also evident, although smaller, from July to October (Fig. S15g-j). Again, however, the details of the circulation trends vary from month to month (Fig. S10).

\subsection{Amazonia}

In central Amazonia $\left(2.5^{\circ}-10^{\circ} \mathrm{S}, 50^{\circ}-65^{\circ} \mathrm{W}\right)$, the trajectory model explains, on average, $57 \%$ of the interannual temperature variability (Fig. 14a)-less than in most extratropical land areas but more than in most parts of the tropics (Fig. 1). The ERA5 39-year temperature trends show a warming varying from $0.5{ }^{\circ} \mathrm{C}$ in February and March to $2.3{ }^{\circ} \mathrm{C}$ in August and September (Fig. 14b). This seasonality appears to be partly although not completely (Fig. 14c) due to atmospheric circulation, which has had a modest effect in the first half-year but has amplified the warming by $0.7-1.0^{\circ} \mathrm{C}$ from August to October. The smaller seasonality in the residual warming agrees better with the trends in the CMIP5 simulations, although both the reanalysed warming and the residual warming fall towards the lower end of the CMIP5 trends in most months of the year (Fig. 14d).

Due to the small temperature gradients in the tropics (Sobel et al. 2001), the circulation-related temperature trends are unlikely to be dominated by horizontal advection. However, the circulation-related temperature anomalies in Amazonia have a strong positive correlation (0.57-0.92, depending on month) with the interannual variations of $\omega(550 \mathrm{hPa})$ (red line in Fig. 15a). Thus, positive circulation-related temperature anomalies coincide with anomalous sinking motion in the mid-troposphere. A similarly high correlation is found between the circulation-related temperature anomalies and the surface net short-wave radiation (blue line in Fig. 15a), the latter being even more strongly correlated with $\omega(550 \mathrm{hPa})$ (black line). Further analysis reveals that this relationship is dominated by variations in the shortwave cloud forcing. Thus, in this case, the signal found by the trajectory method mainly reflects a circulation effect on diabatic heating.

The positive circulation-related temperature trends around September (Fig. 14b) are associated with positive trends is both $\omega(550 \mathrm{hPa})$ and surface net short-wave radiation (Fig. 15b). Interpreting this against the seasonality of vertical motion in Amazonia, this represents a lengthening of the relatively dry season in the Southern Hemisphere winter. Conversely, in the wet season in February and March, a negative trend in $\omega(550 \mathrm{hPa})$ has occurred signifying increasing rising motion. However, this has had a more modest effect on the net short-wave radiation and the diagnosed circulation-related temperature trend is close to zero (Fig. 14b). The connection of these trends to SST changes is an important topic for further research. On the interannual time scale, circulation-related temperature anomalies 
in Amazonia are positively correlated with eastern tropical Pacific SSTs (and thus El Niño-Southern Oscillation variability) in most months of the year, but the correlation is weak in August and September when the circulation-related warming is largest (not shown).

\section{Fourier analysis of temperature trends}

The examples in the previous section suggest two general features. First, the residual trends are typically closer to the CMIP5 multi-model mean than the original ERA5 temperature trends. Second, the effects of atmospheric circulation tend to vary strongly from month to month, and have therefore less impact on the annual mean of temperature trends than on the details of their seasonal cycle. Nevertheless, it is prudent to study whether these conclusions hold in more general terms. To do this, the 12-month seasonal cycle of temperature trends at each grid point was first decomposed into a six-component Fourier series

$\Delta T_{t}=a_{0}+\sum_{n=1}^{6}\left(a_{n} \cos \left(\frac{2 \pi \mathrm{nt}}{12}\right)+\mathrm{b}_{n} \sin \left(\frac{2 \pi \mathrm{nt}}{12}\right)\right)$

where $t \in[1,12]$ is the number of month. Then, using the orthogonality of the Fourier components, the mean square amplitude of the monthly trends was decomposed at each grid point to the contributions of the annual mean change (component 0 ) and seasonal (components 1-2) and sub-seasonal variations (components 3-6). The global averages of these three contributions are given in Fig. 16a and the corresponding mean values for land and sea separately in Fig. 16b, c. The main conclusions are the same for all three areas:
1. For both ERA5, the residual and the CMIP5 multi-model mean, most of the mean square amplitude comes from the annual mean temperature trend. Seasonal and subseasonal variations in the trends are smaller.

2. The circulation-related trends are dominated by their seasonal and sub-seasonal components. Annually averaged circulation-related trends are small.

3. The seasonal and particularly sub-seasonal variations are smaller for the residual trends than for the original ERA5 trends. Thus, the residual trends typically have a less pronounced and smoother seasonal cycle.

4. The seasonal variation in the CMIP5 multi-model mean trends is even weaker than that in the residual trends, and the sub-seasonal variation is negligible.

5. The residual trends are closer to the CMIP5 multi-model mean than the original ERA5 trends are (the two rightmost bars in Fig. 16a-c). This primarily applies to the seasonal and sub-seasonal components of the trends, whereas the difference for the annual mean trends is much smaller. Given the relative smallness of the seasonal and sub-seasonal trend components in the CMIP5 multi-model mean, this improved agreement is largely a direct consequence of the smoother seasonal cycle in the residual than in the original ERA5 trends.

Quantitatively, subtraction of the circulation-related trends from ERA5 reduces the difference to the CMIP5 multi-model mean more in land than sea areas. This is unsurprising, since the circulation-related trends are generally larger over land than sea. Over the global land area, the total mean square difference to CMIP5 is $42 \%$ smaller for the residual trends. The mean square difference of the annual mean trends in land grid points is only reduced by $6 \%$, while
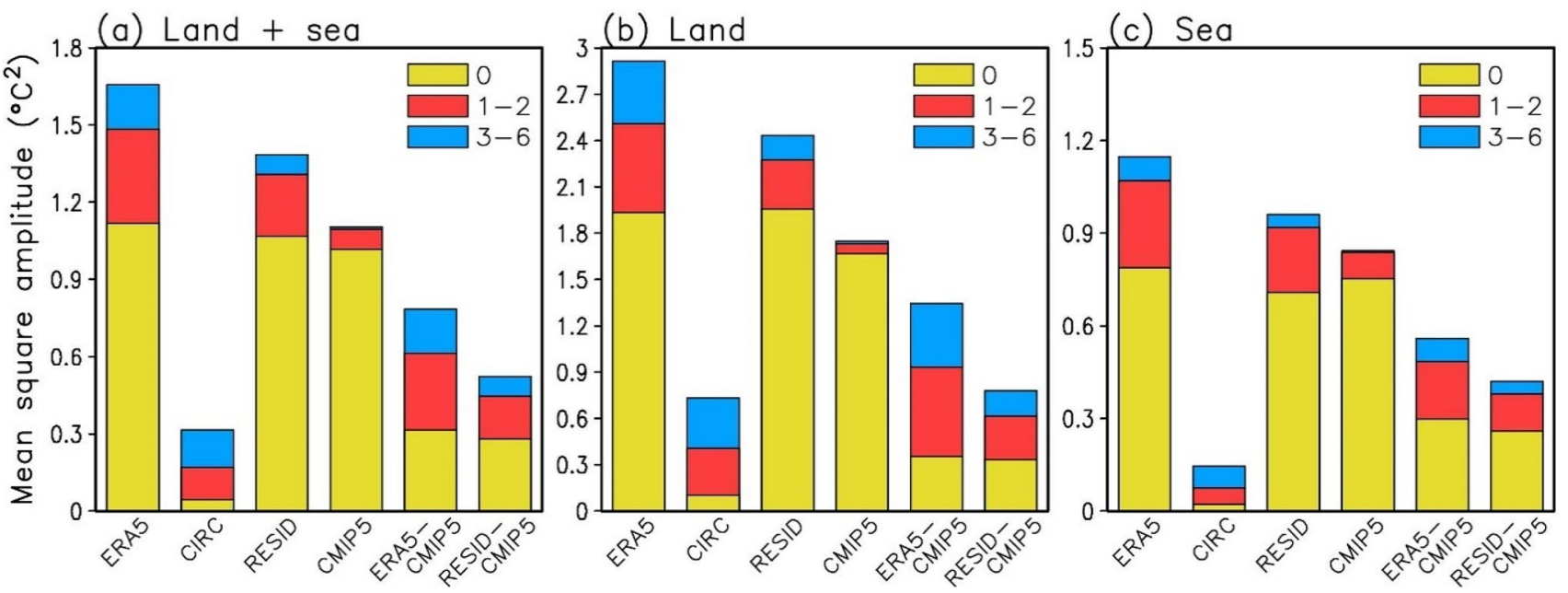

Fig. 16 Mean square amplitudes of the 1979-to-2018 monthly temperature trends decomposed to the contributions of Fourier components 0 (the annual mean, yellow), 1-2 (red) and 3-6 (blue). From left to right: ERA5 trends, circulation-related trends, residual trends, CMIP5 multi-model mean trends, and the trend differences ERA5CMIP5 and residual - CMIP5. a Global, b land only, c sea only 
the differences in the seasonal and sub-seasonal variations are reduced by $51 \%$ and $60 \%$, respectively (two rightmost bars in Fig. 16b).

\section{Comparison with earlier studies}

This section briefly explores two questions: (1) how do the circulation-related temperature trends depend on the period used in the analysis, and (2) how sensitive are they to the method used for their quantification? To this end, three regions are selected: the contiguous United States, the Irkutsk region in Siberia and Europe. For the former two, Fig. 6 of Smoliak et al. (2015) provides time series of observed and adjusted NDJFMA mean temperature up to the year 2011, from which the effect of atmospheric circulation can be estimated as a residual after digitizing the data. For Europe, Saffioti et al. (2016) give an observed 1989-to-2012 DJF mean temperature trend of $-0.37^{\circ} \mathrm{C}$ decade $^{-1}$ and an adjusted trend of $0.42{ }^{\circ} \mathrm{C}$ decade ${ }^{-1}$, implying a circulationrelated trend of $-1.8^{\circ} \mathrm{C}$ in 23 years.

Table 2 summarizes the circulation-related temperature trends in the mentioned three cases for four periods: 1965-2000 (the main focus in Smoliak et al. 2015), 1980-2011 (the longest period common to Smoliak et al. and this study, when using contiguous winters starting from the previous year), either 1989-2012 as used by Saffioti et al. (2016) for Europe or 1989-2011 for the other two regions, and the years 1979-2018 used in the previous sections. The second and third of these periods inform on the methoddependence of the trends, while the first and the last only inform on their period-dependence.

The main message from Table 2 is the strong perioddependence of the circulation-related trends. In particular, the NDJFMA trends in the Irkutsk region using the Smoliak et al. (2015) method vary from a warming of $1.4{ }^{\circ} \mathrm{C}$ in 1965-2000 to a cooling of $2.1^{\circ} \mathrm{C}$ in 1989-2011. Similarly, both Saffioti et al. (2016) and the present method indicate a circulation-related winter cooling of $1.8{ }^{\circ} \mathrm{C}$ in Europe in
1989-2012, but the trend for 1979-2018 using the present method is marginally positive. These differences indirectly support the view that much of the observed circulation variability has been caused by the internal dynamics of the climate system, rather than by gradually increasing greenhouse gas concentrations. They also stress the need for extreme caution when comparing studies made for different periods.

Second, there is good agreement between the trends found for the common periods of this and the two other studies. As the largest difference, the present method indicates an even larger circulation-related NDJFMA cooling in the Irkutsk region in 1980-2011 and 1989-2011 than Smoliak et al. (2015). Nevertheless, this sample of examples is small. To find out whether this good agreement generalizes to other seasons, regions and methods, a more systematic comparison between different methods using the same data sets and periods of analysis would be worthwhile.

\section{Conclusions}

In this study, the effect of atmospheric circulation on surface air temperature trends during the period 1979-2018 was analysed using a trajectory-based method. With some exceptions, including for example reduced warming in western Siberia and increased warming in central Europe and the Arctic Ocean, the circulation effect on the annual mean temperature trends was found to be relatively modest. However, the effect on seasonal and, in particular, monthly temperature trends has been more substantial. Subtracting the effect of circulation changes from the ERA5 temperature trends leaves residual trends that have a smoother annual cycle than the original trends and are typically closer to the CMIP5 multi-model mean. As averaged over the global land area, the mean square difference from the CMIP5 multimodel mean is $42 \%$ smaller for the residual trends than for the original ERA5 monthly mean temperature trends, although the difference in annual mean temperature trends is only reduced by $6 \%$.
Table 2 Comparison of temperature trends $\left({ }^{\circ} \mathrm{C}\right.$ from the beginning to the end of the period) between this study, Smoliak et al. (2015; SMOL) and Saffioti et al. (2016; SAFF)

\begin{tabular}{|c|c|c|c|c|c|c|}
\hline \multirow[b]{2}{*}{ Period } & \multicolumn{2}{|c|}{ Contiguous US $^{1}$} & \multicolumn{2}{|c|}{ Irkutsk region $^{2}$} & \multicolumn{2}{|c|}{ Europe $^{3}$} \\
\hline & SMOL & This study & SMOL & This study & SAFF & This study \\
\hline 1965-2000 & 0.5 & $\mathrm{n} / \mathrm{a}$ & 1.4 & $\mathrm{n} / \mathrm{a}$ & $\mathrm{n} / \mathrm{a}$ & $\mathrm{n} / \mathrm{a}$ \\
\hline 1980-2011 & 0.0 & 0.2 & -0.8 & -1.1 & $\mathrm{n} / \mathrm{a}$ & 0.1 \\
\hline $1989-2011 / 2012^{4}$ & -0.1 & -0.1 & -2.1 & -2.7 & -1.8 & -1.8 \\
\hline 1979-2018 & $\mathrm{n} / \mathrm{a}$ & 0.1 & $\mathrm{n} / \mathrm{a}$ & -0.8 & $\mathrm{n} / \mathrm{a}$ & 0.2 \\
\hline
\end{tabular}

$n / a$ not available

${ }^{1}$ Land at $\left(25^{\circ}-50^{\circ} \mathrm{N}, 65^{\circ}-125^{\circ} \mathrm{W}\right)$, November to April

${ }^{2}$ Land at $\left(50^{\circ}-65^{\circ} \mathrm{N}, 90^{\circ}-120^{\circ} \mathrm{E}\right)$, November to April

${ }^{3}$ Land at $\left(35.75^{\circ}-72^{\circ} \mathrm{N}, 12^{\circ} \mathrm{W}-42^{\circ} \mathrm{E}\right)$, December to February

${ }^{4}$ End year is 2012 for Europe and 2011 for the other regions 
As discussed in the introduction, (1) atmospheric circulation may be to some extent affected by external forcing and (2) internal climate variability may be generated by variations in sea surface conditions even in the absence of atmospheric circulation changes. Due to these two caveats, the quantification of the circulation effect (even if this could be done perfectly) cannot exactly quantify the effect of internal variability on the observed temperature trends. Nonetheless, it is still expected to give a useful approximation, particularly in extratropical areas where the climatological temperature gradients are large. Therefore, the subtraction of the circulation effect should generally give a better estimate of the forced (mainly anthropogenic) temperature changes than observed temperature changes as such do.

Acknowledgements This work was supported by the Academy of Finland (decisions 307331 and 316704). Three anonymous reviewers are acknowledged for their constructive comments that helped to improve the original manuscript.

Data availability The ERA5 reanalysis data were downloaded from the Copernicus Climate Change Service (https://climate.copernicus.eu/ climate-reanalysis) and the CMIP5 climate model data from the Earth System Grid Federation data archive (https://esgf-node.llnl.gov/searc h/cmip5/). Data and GrADS (http://cola.gmu.edu/grads/) scripts that allow the user to generate figures similar to Figs. 4, 6, 8, 10, 12, 14 and S17-S22 for an arbitrary area are available at https://github.com/jarai san/circulation and https://doi.org/10.5281/zenodo.4314425.

Open Access This article is licensed under a Creative Commons Attribution 4.0 International License, which permits use, sharing, adaptation, distribution and reproduction in any medium or format, as long as you give appropriate credit to the original author(s) and the source, provide a link to the Creative Commons licence, and indicate if changes were made. The images or other third party material in this article are included in the article's Creative Commons licence, unless indicated otherwise in a credit line to the material. If material is not included in the article's Creative Commons licence and your intended use is not permitted by statutory regulation or exceeds the permitted use, you will need to obtain permission directly from the copyright holder. To view a copy of this licence, visit http://creativecommons.org/licenses/by/4.0/.

\section{References}

Collins M et al (2013) Long-term climate change: projections, commitments and irreversibility. In: Stocker T et al (eds) Climate change 2013: the physical science basis. Contribution of Working Group I to the Fifth Assessment Report of the Intergovernmental Panel on Climate Change. Cambridge University Press, Cambridge, pp 1029-1136

Deser C, Phillips A, Bourdette V, Teng H (2012) Uncertainty in climate change projections: the role of internal variability. Clim Dyn 38:527-546

Deser C, Phillips AS, Alexander MA, Smoliak BV (2014) Projecting North American climate over the next 50 years: uncertainty due to internal variability. J Clim 27:2271-2296

Deser C, Terray L, Phillips AS (2016) Forced and internal components of winter air temperature trends over North America during the past 50 years: Mechanisms and implications. J Clim 29:2237-2258
Hawkins E, Sutton R (2009) The potential to narrow uncertainty in regional climate predictions. Bull Am Meteorol Soc 90:1095-1107

Hawkins E, Sutton R (2010) The potential to narrow uncertainty in projections of regional precipitation change. Clim Dyn 37:407-418

Hersbach H, et al (2020) The ERA5 global reanalysis. Q J R Meteorol Soc. https://doi.org/10.1002/qj.3803

Holmes CR, Woollings T, Hawkins E, de Vries H (2016) Robust future changes in temperature variability under greenhouse gas forcing and the relationship with thermal advection. J Clim 29:2221-2236

Hurrell JW, van Loon H (1997) Decadal variations in climate associated with the North Atlantic Oscillation. Clim Change 36:301-326

Iles C, Hegerl G (2017) Role of the North Atlantic Oscillation in decadal temperature trends. Environ Res Lett 12:114010

Parker DE (2009) Anomalies of Central England Temperature classified by air source. J Clim 22:1069-1081

Polvani LM (2011) Stratospheric ozone depletion: the main driver of twentieth-century atmospheric circulation changes in the Southern Hemisphere. J Clim 24:795-812

Power S, Delage F, Wang G, Smith I, Kociuba G (2017) Apparent limitations in the ability of CMIP5 climate models to simulate recent multi-decadal change in surface temperature: implications for global temperature projections. Clim Dyn 49:53-69

Räisänen J (2019a) Energetics of interannual temperature variability. Clim Dyn 52:3139-3156

Räisänen J (2019b) Effect of atmospheric circulation on recent temperature changes in Finland. Clim Dyn 53:5675-5687

Räisänen J, Ylhäisi JS (2011) How much should climate model output be smoothed in space? J Clim 24:867-880

Rosenblum E, Eisenman I (2017) Sea ice trends in climate models only accurate in runs with biased global warming. J Clim 30:6265-6278

Saffioti C, Fischer EM, Scherrer SC, Knutti R (2016) Reconciling observed and modelled temperature and precipitation trends over Europe by adjusting for circulation variability. Geophys Res Lett 43:8189-8198

Saffioti C, Fischer EM, Knutti R (2017) Improved consistency of climate projections over Europe after accounting for atmospheric circulation variability. J Clim 30:7271-7291

Scherrer SC, Begert M (2019) Effects of large-scale atmospheric flow and sunshine duration on the evolution of minimum and maximum temperature in Switzerland. Theor Appl Climatol 138:227-235

Selten FM, Branstator GW, Dijkstra HA, Kliphuis M (2004) Tropical origins for recent and future Northern Hemisphere climate change. Geophys Res Lett 31:L21205

Smoliak BV, Wallace JM, Lin P, Fu Q (2015) Dynamical adjustment of the Northern Hemisphere surface air temperature field: methodology and application to observations. J Clim 28:1613-1629

Sobel AHJ, Nilsson J, Polvani LM (2001) The weak temperature gradient approximation and balanced tropical moisture waves. J Atmos Sci 58:3650-3665

Taylor KE, Stouffer RJ, Meehl GA (2012) An overview of CMIP5 and the experiment design. Bull Am Meteorol Soc 93:485-498

Thompson DWJ, Wallace JM (1998) The Arctic Oscillation signature in the wintertime geopotential height and temperature fields. Geophys Res Lett 25:1297-1300

van Vuuren DP et al (2011) The representative concentration pathways: an overview. Clim Change 109:5-31

Wallace JM, Fu Q, Smoliak BV, Lin P, Johanson CM (2012) Simulated versus observed patterns of warming over the extratropical Northern Hemisphere continents during the cold season. Proc Natl Acad Sci USA 109:14337-14342

Publisher's Note Springer Nature remains neutral with regard to jurisdictional claims in published maps and institutional affiliations. 